Article

\title{
Contribution of Driving Efficiency and Vehicle-to-Grid to Eco-Design
}

\author{
David Borge-Diez $1, * \mathbb{C}$, Pedro Miguel Ortega-Cabezas ${ }^{2}$, Antonio Colmenar-Santos ${ }^{2} \mathbb{C}$ \\ and Jorge-Juan Blanes-Peiró ${ }^{1}$ \\ 1 Department of Electrical and Control Engineering, Universidad de León, 24007 León, Spain; \\ jorge.blanes@unileon.es \\ 2 Department of Electric, Electronic and Control Engineering, UNED, 28040 Madrid, Spain; \\ pedro.ortegacabezas@gmail.com (P.M.O.-C.); acolmenar@ieec.uned.es (A.C.-S.) \\ * Correspondence: david.borge@unileon.es
}

Received: 26 June 2020; Accepted: 26 July 2020; Published: 3 August 2020

\begin{abstract}
Designing eco-friendly products involves energy efficiency improvements. Eco-friendly products must consider not only raw materials and manufacturing processes to improve energy efficiency but also energy needed when designing them. This research shows how eco-routing (ER), eco-charging (EC), eco-driving (EDR), vehicle-to-grid (V2G) and electric vehicles (EVs) can contribute to the reduction of energy consumption during product design. To do this, a group of 44 engineers assigned to the project was chosen to assess the total energy available for V2G when driving EVs from their homes to the design center by using ER, ED and EC by running an application coded by the authors. The energy stored in EVs was used to quantify the reduction in energy consumption of the buildings present in the design center. The results show that the energy saving ranges from $2.89 \%$ to $6.9 \%$ per day-in other words, $93 \mathrm{kWh}$ per day during the design process. In addition, the fact of making the design process greener implies that renewable energies (REs) are integrated better during the design process. By running the application, drivers are informed about the RE mix when the charging process takes place. Finally, this research shows that current policies make V2G and vehicle-to-home techniques not compatible.
\end{abstract}

Keywords: eco-design; energy efficiency; eco-routing; eco-charging; eco-driving; renewable energies

\section{Introduction}

Eco-design allows implementing eco-friendlier products as environmental impacts are considered during the design phase [1,2]. Several factors which influence eco-design have been identified in several research [3-6]. Among them, one can find: manufacturing without producing hazardous waste, using clean technologies, reducing product chemical emissions and product energy consumption, using recycle materials and reusing components, designing products for ease of disassembly and reusing or recycling products at the end of their lives [7]. Some proposals have been made to improve these factors. Morgan and Liker [8] pushed to use lean manufacturing in design when developing products. As detailed by Rosen and Kishawy [9], this usage could imply that several alternatives used during the project can be assessed and, consequently, costs and benefits of eco-design can be set. When it comes to energy efficiency, research is mainly focused on final products and manufacturing processes. The former deals with the energy labelling concept which allows companies to create labels indicating the product energy efficiency [10]. The latter includes reducing energy consumption during the manufacturing process. Seow et al. described a new outlook called "Design for Energy Minimization" aiming to provide transparency regarding energy consumption during the manufacturing process to help inform design decisions [11]. Ka-Leung-Moon et al. proposed guidelines for the design and 
production of sustainable energy-saving fashion products [12]. Renewable energy (RE) integration plays an important role in eco-design. As detailed by Crul, Diehl and Ryan [13], considering that the number of products that need electricity is increasing rapidly, it is of paramount importance to incorporate them in the design process. In their dissertation, they proposed guidelines to integrate REs in the final product. Finally, waste is an important topic to be considered. For example, cybersecurity is a source of waste as detailed later. Tecchio et al. performed a detailed analysis of the potentials of material efficiency to guarantee waste prevention and material reuse [14].

In addition to the manufacturing process, one can find many activities which generate pollutants during product design. Among them, one can find: software validation processes, prototype product testing and building energy consumption [15-17]. Even emissions generated when engineers involved in projects commute to work impact eco-design. Software validation is an essential activity when designing automotive electronic control units (ECUs) $[15,18]$. To do this, prototype vehicles and a considerable number of hours of hardware-in-the-loop simulation are needed $[19,20]$. Consequently, pollution is caused. When designing combustion engines, activities such as engine tuning and driving tests cause pollution. However, the engine design process lacks both guidelines and policies to limit emissions during engine development contrary to the vehicles which have already been marketed and whose emission limits are clear and strict. Building efficiency is an essential topic which contributes to emission reduction as detailed in the literature [21-23]. Finally, the vehicles used by the engineers who are involved in any projects are a source of pollution when commuting to their work. Some factors analyzed in this study such as the number of engineers participating in the project and the location of their homes regarding the design center may decrease or increase emissions.

Eco-routing (ER), eco-driving (EDR) and eco-charging (EC) have an impact on energy efficiency when it comes to eco-design as analyzed in this research. EDR includes all driving habits which could reduce energy consumption and emissions. Nowadays, most cars are equipped with the system that informs how efficient the way of driving is. Qi et al. [24] investigated EDR by quantifying the energy potentially saved when applying to electric vehicles (EVs). Sabrina et al. [25] also proposed a similar work in which continuous and on-demand feedback on driving behavior and safety was conducted. Zhan et al. [26] discussed how systems in charge of monitoring the EV battery improve energy efficiency. ER helps the driver to find the most efficient route to go from point $A$ to $B$ considering several parameters such as real-time traffic conditions, road types and gradient, passengers' and cargo weight. Nunzio, Thibault and Sciaretta [27] implemented a new model based on speed fluctuations and a road network infrastructure to set the best route. The University of California has worked on systems which are able to collect energy consumption data in real-world driving conditions with the aim of integrating them into eco-route algorithms [28]. In this research, EC measures the contribution of RE when charging EVs, showing the optimal moments to do this.

Energy consumption of buildings can be reduced by following several options. Haque and Raham described in their study a comparison between solar photovoltaic mini-grid pumped hydroelectric storage versus battery storage [29]. Their main conclusion was that pumped storage is almost half as efficient yet more expensive than conventional battery storage. Another option to reduce energy consumption is the usage of buildings which integrate photovoltaic energy as described by Haque, Rahman and Ahsan [30]. Vehicle-to-grid (V2G) technology allows a better integration of REs and energy peak reduction [31,32]. Nevertheless, V2G technology is completely influenced by policies and battery degradation as detailed by Uddin, Dubarry and Glick [33]. Consequently, it is of paramount importance to analyze V2G from different social dimensions [34].

Finally, cybersecurity aims to protect ECUs from being violated by modifying the internal code and calibration. Of course, this could lead to critical situations where someone could take control of the vehicle. Several strategies can be followed. For example, a gateway can be integrated into the network architecture with the aim of keeping ECUs from being accessed in a reading or writing mode from an external computer unless this computer is connected to the manufacturer's network. Generally, an ECU stores several keys needed to assure its integrity. If an ECU fails, it must be analyzed whether 
there is a hardware or software problem. To do this, the security must be disabled. After that process, the ECU is not allowed to be installed in the vehicle again. As shown in this research, at that moment, the ECU is scrapped.

This research formulates a proposal to reduce emissions by using energy savings during product design based on ER, EDR, EC, EVs and V2G. This study, which was done on an ECU supplier in Europe when developing new products, has three goals. Firstly, it proposes an algorithm based on EVs, ER, EDR and EC with the aim of improving energy efficiency and RE integration in the product design process by using the Here ${ }^{\circledR}$ application programming interface (API) provided by Here $^{\circledR}$ (Eindhoven, Holland), the data published by the French system operator (The system operator is responsible for coordinating electricity supply and demand in real time in a manner that avoids fluctuations in frequency or disruption of supply. This requires maintaining a continuous balance between the electricity supply from generators and demand from consumers, while ensuring that appropriate reserves are available to manage any system events.) and neural networks [35]. Secondly, this study shows how ER, EDR, EC and V2G contribute to eco-design by reducing emissions during product design. In addition, compatibility between V2G and vehicle-to-home (V2H) is analyzed. Finally, this research also describes how cybersecurity impacts eco-design and how it could involve more waste generation.

The paper is organized as follows. Section 2 describes the method used in this research. Section 3 displays the results obtained. Section 4 discusses these results and, finally, Section 5 draws the main conclusions of this research.

\section{Methods}

This section is organized as follows. Section 2.1 describes the method used in this study. Section 2.2 explains the trips made as well as the number of engineers chosen for this study. Section 2.3 displays the equipment employed. Section 2.4 describes the algorithm implementation. Section 2.5 displays the method used to analyze data statistically. Section 2.6 briefly introduces the concept of V2G. Section 2.7 analyzes the main topics linked to cybersecurity.

\subsection{Overview of the Methods Used}

When it comes to the method (Figure 1), two key points must be considered to assess the contribution of ED, EDR and EC to eco-design. The former consists of choosing the optimal locations and the number of engineers participating in this research. The latter shows how the algorithm works and its implementation. To do this, the Here ${ }^{\circledR}$ API was used to determine the best route considering EC, EDR and ER models based on data from the vehicle control unit (VCU), traffic state, drivers' habits (the way of using the accelerator or brake pedals among other data), current battery capacity and potential recharge needs among others [35-37]. In addition, the EC concept shows drivers when a recharge process might be necessary, taking into account when the RE contribution is higher.

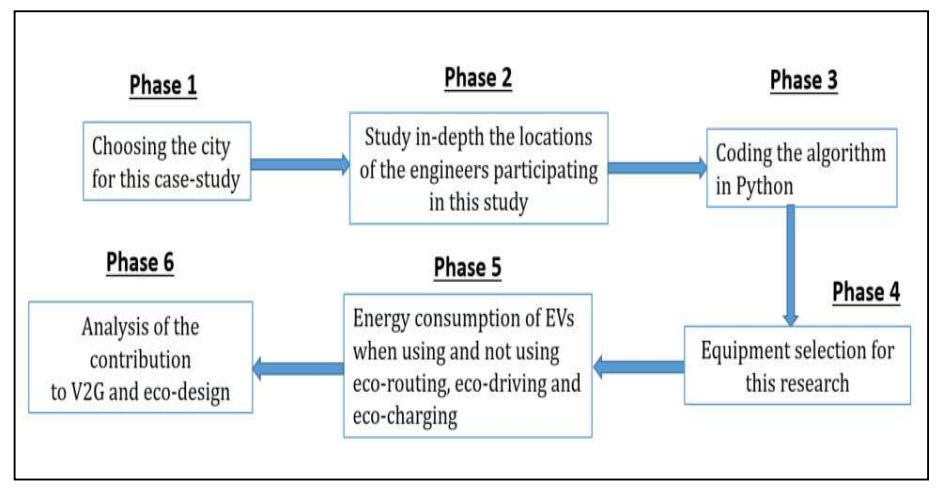

Figure 1. Method followed in this research. 


\subsection{Description of Trips}

Figure 2 and Table 1 depict the number of engineers participating in this study, the locations where these engineers live and the distance from each location to the design center. These locations were chosen to cover all parts of the city (north, south, east and west of Toulouse) and the number of engineers was assigned depending on traffic conditions in such a way that the more traffic jams were close to the location, the bigger number of engineers was chosen. All vehicles used were equipped with a $40-\mathrm{kWh}$ battery. Their autonomy was close to $250 \mathrm{~km}$. The maximum speed was $144 \mathrm{~km} / \mathrm{h}$, and the engine torque was around $320 \mathrm{Nm}$.

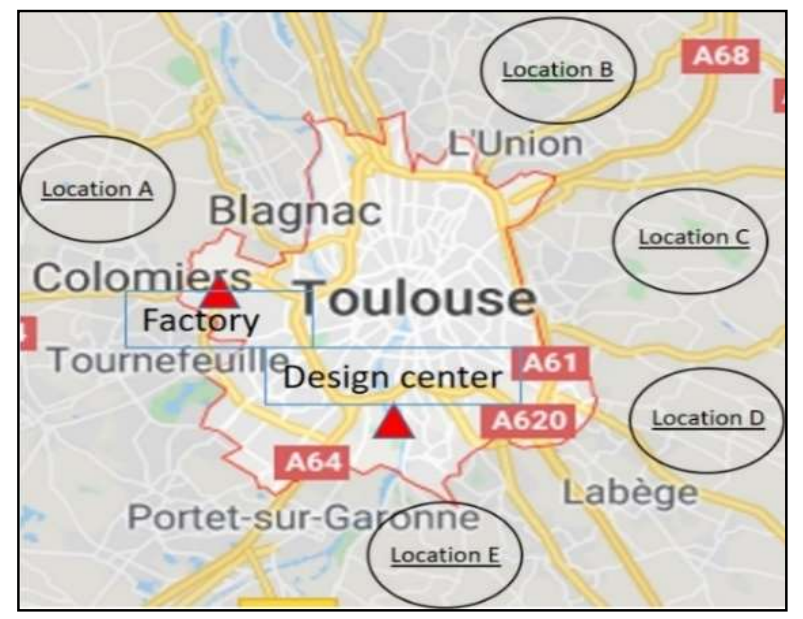

Figure 2. Locations of engineers assigned to the project.

Table 1. Distance between locations and the design center.

\begin{tabular}{cccc}
\hline From & To & Distance $\mathbf{( k m )}$ & Number of Engineers \\
\hline Location A & & 24 & 10 \\
Location B & & 20 & 8 \\
Location C & Design center & 26 & 8 \\
Location D & & 22 & 12 \\
Location E & & 19 & 6 \\
\hline
\end{tabular}

The trips were made in 2019 with the aim of collecting important data such as energy consumption by using the equipment described in Section 2.3.

\subsection{Equipment}

The following means were used in this research:

1. The software and hardware of a VCU used by the company subjected to this case-study was designed by one of the most important European suppliers specialized in embedded systems;

2. All vehicles employed in this study were EVs equipped with a 40-kWh battery;

3. Throughout this research, it is necessary to make measurements of different software variables stored in the VCU memory. In this study, the Inca ${ }^{\circledR}$ software provided by ETAS ${ }^{\circledR}$ (Stuttgart, Germany) was used as it allows reading memory locations/software variables in real time [38]; Here ${ }^{\circledR}$ and Open Charge Map ${ }^{\circledR}$ APIs with the aim of choosing the best route and showing the closest battery charger locations [35,39]. Open Charge Map is a non-commercial, non-profit, electric vehicle data service hosted and supported by a community of businesses, charities, developers and interested parties around the world;

4. The MDA ${ }^{\circledR}$ software provided by ETAS ${ }^{\circledR}$ (Stuttgart, Germany) to analyze all data acquisition [40]. 


\subsection{Algorithm Used in This Research}

The algorithm provided in the Supplementary Data and used in this research is depicted in Figure 3. First of all, the energy consumption models available in the Here ${ }^{\circledR}$ API are tuned [36]. Then, the driver sets the destination by using a web interface. Afterwards, the algorithm assesses the optimal route for the driver. To do this, the Here ${ }^{\circledR}$ API is called by the Python code by using the Routingmode parameter [35]. This parameter has an attribute named Type which can take three types of routes: the route that requires the least amount of travel time, the shortest one which reduces and optimizes the distance covered and finally the balanced mode which searches for the correct balance between distance and time (only for trucks). The way how the algorithm works to determine the best routes belongs to the Here ${ }^{\circledR}$ know-how. The Python code receives from the Here ${ }^{\circledR}$ API the potential routes (the shortest, the fastest and the balanced one) to the destination and the energy consumption for each one. The application chooses the one with less energy consumption as explained later. Appendix A provides further information about how to set up Here ${ }^{\circledR}$ to help the reader to reproduce the experiment. Finally, the algorithm runs a block called eco-charging which aims to calculate the RE contribution and energy structure generation (wind power, photovoltaic, etc.) by using neural networks. The driver is, therefore, informed about when the charging process is greener.

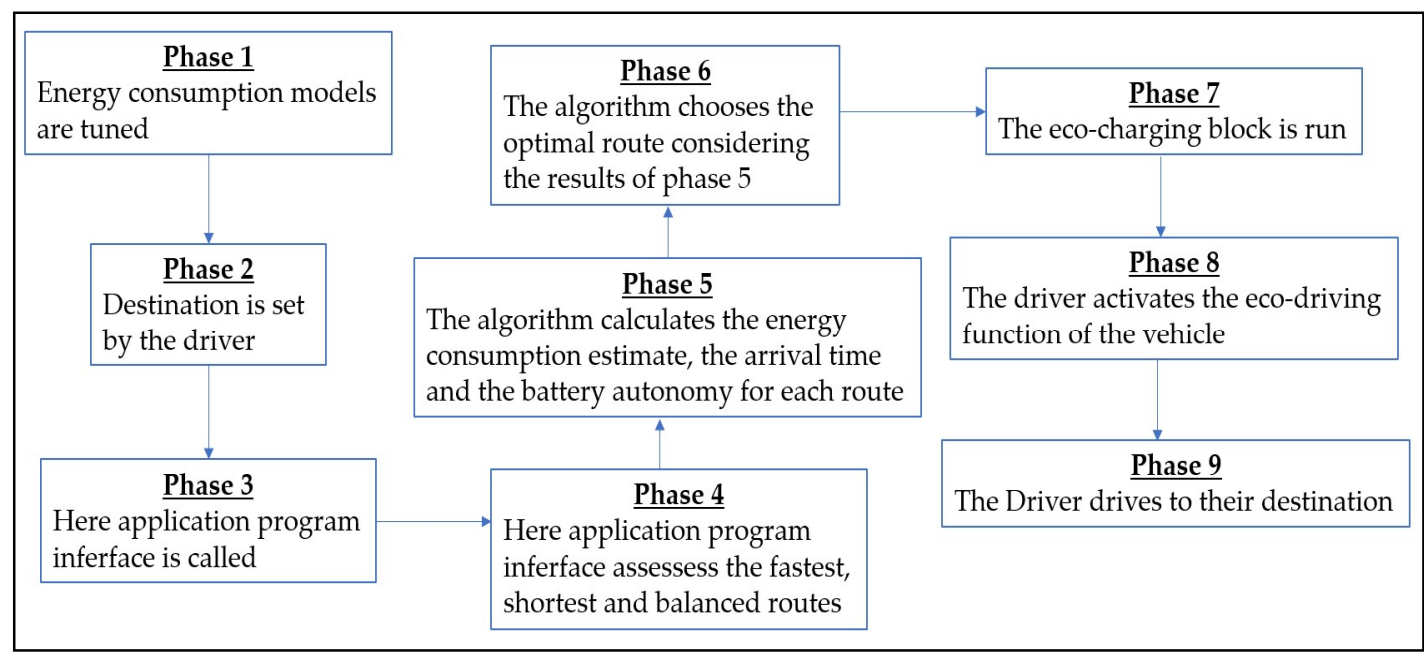

Figure 3. Algorithm description.

Here $^{\circledR}$ API provides energy consumption models that allow assessing energy consumption by using several parameters such as speed, auxiliary energy consumption (radio, cooling/heating, accelerations, decelerations, etc.). The way of tuning these models implies that the value of each parameter in $\mathrm{kWh}$ is provided depending on the speed value (if possible, as not all parameters are linked to speed such as auxiliary systems). In this research, these values were established by performing data acquisition after the drivers participating in this research made each trip 50 times in different periods and traffic conditions (Section 2.2). As shown in Figure 4, the Inca ${ }^{\circledR}$ software installed in a laptop as well as input/output from ETAS ${ }^{\circledR}$ supplier modules were used to perform the data acquisition. Finally, the tuning engineers of the company that collaborated in this study assessed the factors' values by analyzing the data acquisition by using the $\mathrm{MDA}^{\circledR}$ software provided by ETAS ${ }^{\circledR}$ (Stuttgart, Germany) and internal procedures. To introduce this information by using the Here ${ }^{\circledR}$ interface is easy. First of all, the reader must indicate to Here ${ }^{\circledR}$ that the standard energy consumption model will be used. Figure 5 shows an example that helps the reader to reproduce this study. Once these factors are tuned and introduced in the Python code, Here ${ }^{\circledR}$ returns the energy consumption estimate for each type of route (the fastest, the shortest and the balanced one). Consequently, the one with less energy consumption is chosen. Taking into account the initial battery capacity before the trip, the algorithm can determine if a charge is needed during the trip. 


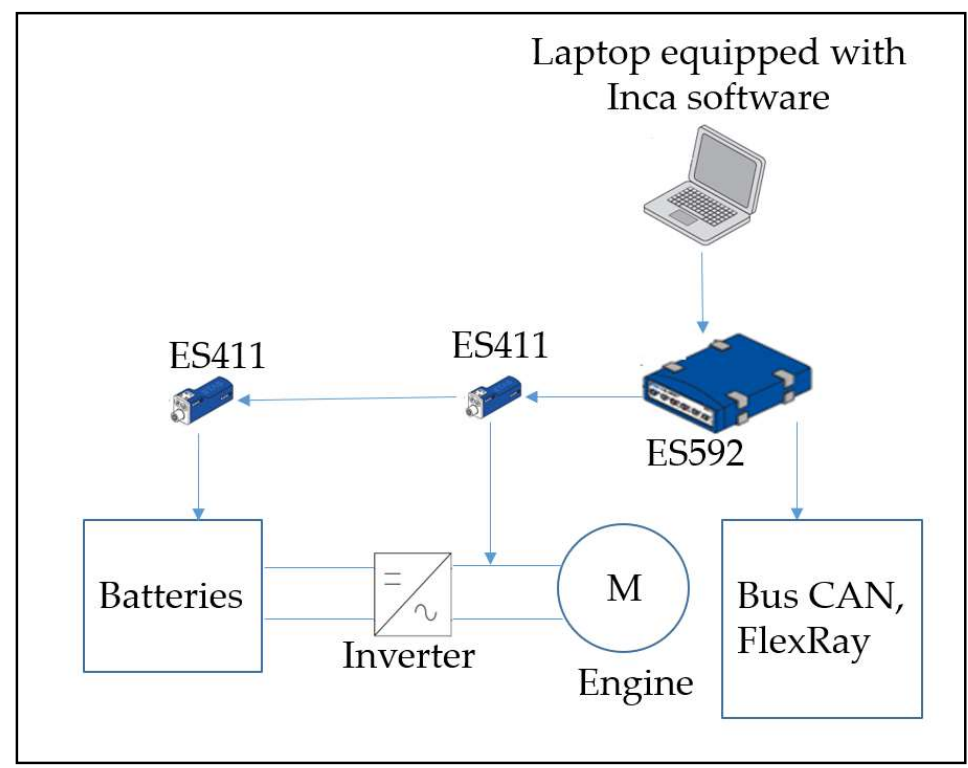

Figure 4. Connection of the laptop to the electric vehicle (EV).

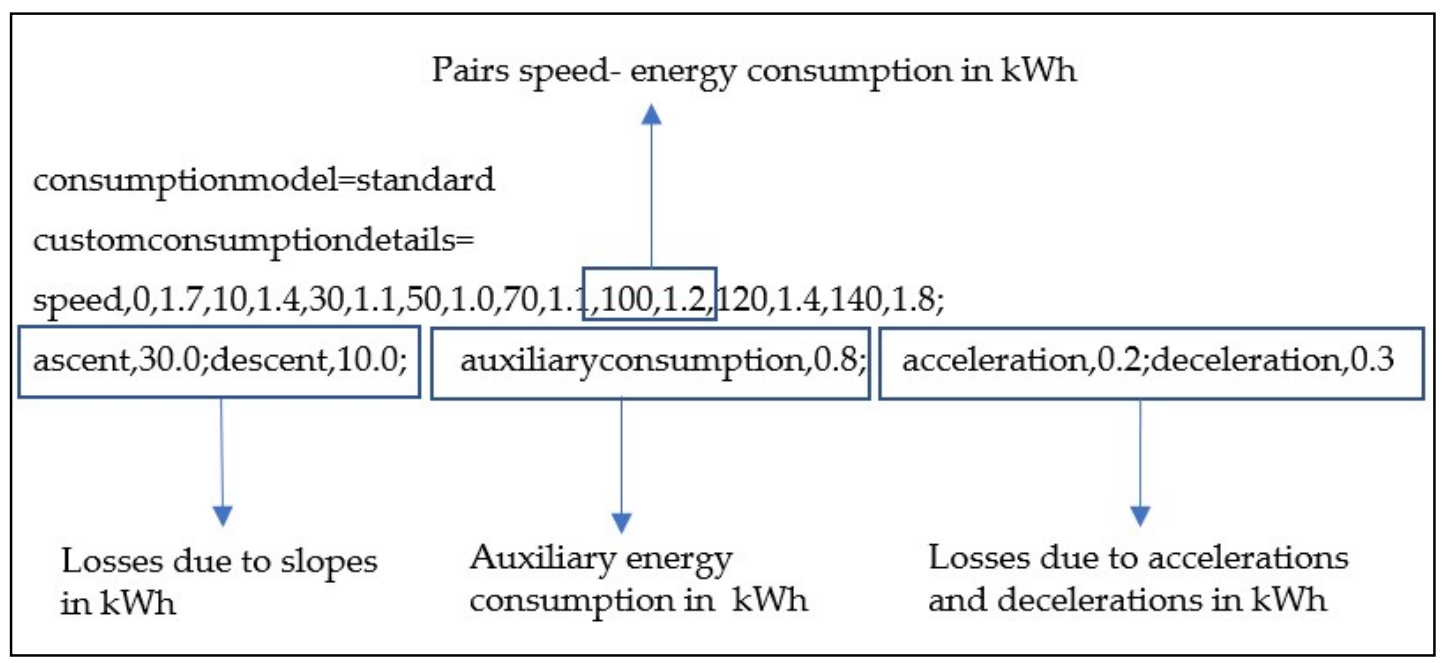

Figure 5. How to configure the energy consumption model.

Finally, the EC block is run, and the eco-score (how REs are integrated into the charging process) is assessed. The aim of this block is to determine the RE contribution when the charging process may take place considering the battery capacity. In addition, an estimate of energy structure (wind power, fuel, etc.) is made. The block is depicted in Figure 6. In phase 1, several factors are analyzed such as the battery capacity and the energy consumption for a specific journey, among others. It must be reminded that the energy consumption was estimated earlier by using the energy consumption model. Furthermore, the most likely time when the charging process takes place can be assessed (phase 2). Therefore, the RE contribution and most likely energy source mix (coal, solar energy, gas, etc.) can be obtained as detailed later by using gated recurrent unit (GRU) networks and nonlinear autoregressive (NAR) neural networks (phase 3) [41-45]. Finally, the EC is assessed considering the RE contribution. In addition, the algorithm proposed in this paper provides information about different parameters such as chargers thanks to Open Charge Map API [35]. 


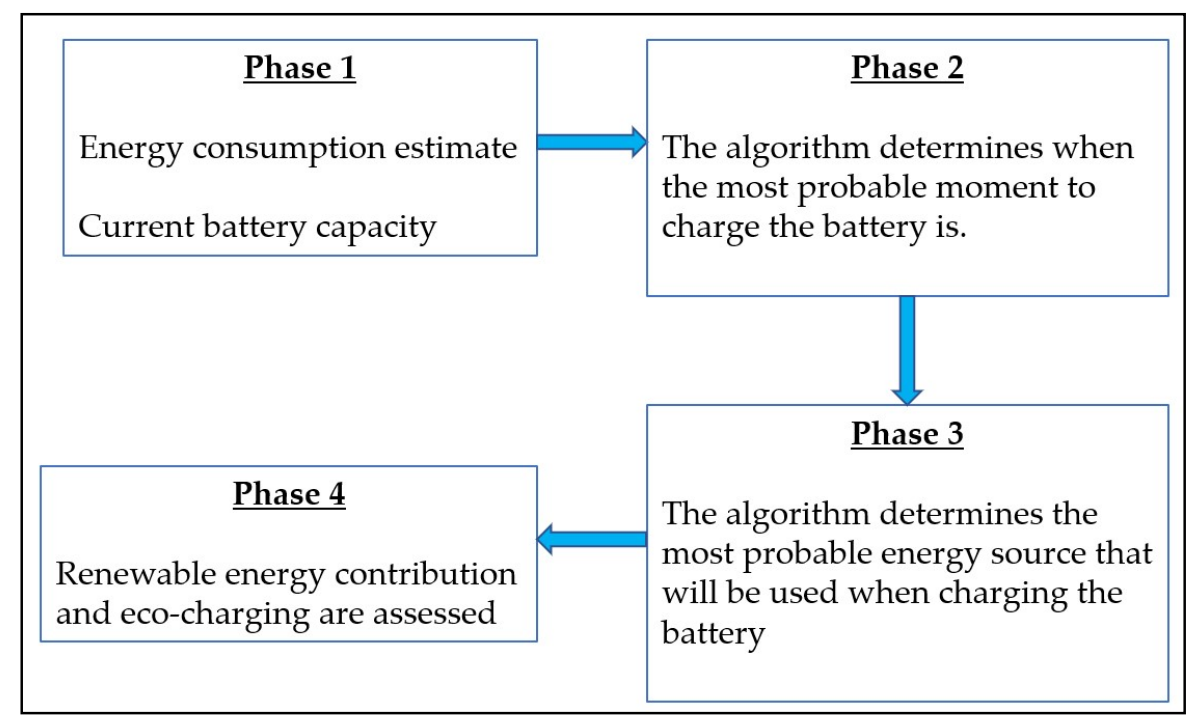

Figure 6. Emissions estimated by using several parameters.

The EC score measures how green the charging process is considering the RE contribution. It can be assessed as given by Equation (1):

$$
E c o-\text { charging }=\frac{R E_{c, t}}{R E_{\max , d}}
$$

where $R E_{c, t}$ is the RE contribution to the total electricity demand at $t$ (in MW) and $R E_{\text {max, }}$ is the maximal $\mathrm{RE}$ contribution (in MW) during the day when the charging process takes place. Both parameters are calculated by using neural networks. RE contribution is measured by using Equation (2):

$$
R E_{c}=\frac{R E}{R E+N R E}
$$

where $R E_{c}$ is the RE contribution (in \%), $R E$ is the total electricity generated by RE sources (in MW) and NRE is the total electricity generated by non-RE such as coal (in MW).

$R E_{c, t}$ and $R E_{\max , d}$ are estimated as follows. The French system operator publishes files on a daily basis in which one can find the $\mathrm{CO}_{2}$ generation structure and the total electricity demand of the day [46]. It must be taken into account that electricity demand and total RE contribution are stationary series. In other words, the pattern is repeated. Only some aspects have to be considered such as weekends and seasons. Anyway, two electricity consumption peaks can be found every day. Consequently, NAR networks are needed to model the electricity demand prediction for a specific day from a desired time (for example, departure planned at 7 p.m.) to midnight. The Python code analyzes the results returned by the neural network and determines the maximum RE contribution of the day. Finally, Equations (1) and (2) are assessed.

Typical recurrent networks present problems when it comes to long-term predictions due to the vanishing gradient problem. Engineers face this problem when training recurrent neural networks with gradient-based learning methods and backpropagation. When using this method, each of the neural network's weights receive an update proportional to the partial derivative of the error function with respect to the current weight in each iteration of training. In some cases, the gradient will be vanishingly small. Consequently, the weight does not change its value, and might stop the neural network training. To enhance long-term predictions, long short-term memory or GRU can be used. In this research, GRUs have been chosen, as they are more efficient (they require less memory). GRU is a recurrent neural network architecture that uses update and reset gates (Figure 7). 


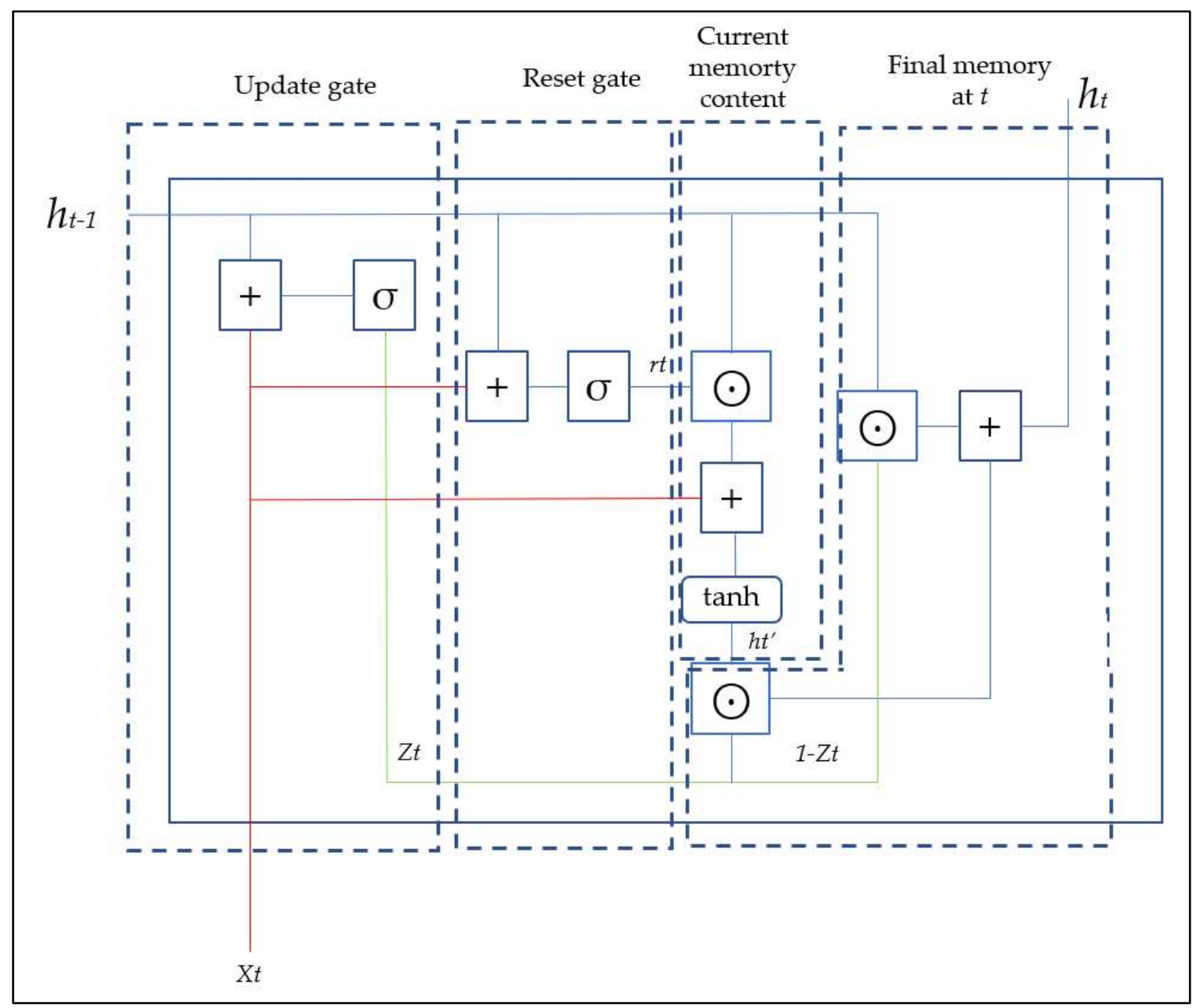

Figure 7. Gated recurrent unit (GRU) architecture.

Mathematically, the process is as follows:

(a) Update gate for time step $t$

The update gate $z_{t}$ is calculated by following Equation (3):

$$
z_{t}=\sigma \times\left(W^{(z)} \times x_{t}+U^{(z)} \times h_{t-1}\right)
$$

where $x_{t}$ is the inputs presented to the network, $W^{(z)}$ is its weight matrix, $h_{t-1}$ holds the information of the previous step $t-1$ and $U^{(z)}$ is its weight matrix. Both results are added, and a sigmoid activation is applied to squash the result between 1 and 0 . The update gate allows determining how much of the past information should be passed along to the future.

(b) Reset gate for time step $t$

It is given by Equation (4).

$$
r_{t}=\sigma \times\left(W^{(r)} \times x_{t}+U^{(r)} \times h_{t-1}\right)
$$

The meaning of this factor is the same as for Equation (3) except $r_{t}$ which is the reset gate. The reset gate corresponds to the past information which must be forgotten.

(c) Current memory content

The new memory content $h_{t}^{\prime}$ uses the reset gate to store relevant information from the past.

$$
h_{t}^{\prime}=\tanh \left(W \times x_{t}+r_{t} \times U \odot h_{t-1}\right)
$$


The meaning of this factor is the same as for Equations (3) and (4). $\odot$ represents the Hadamard product.

(d) Final memory at a current step

In this step, the vector $h_{t}$ is calculated by using Equation (6). This vector holds the information for the current unit and passes it down to the network. To do this, the update gate is needed.

$$
h_{t}=z_{t} \odot h_{t-1}+\left(1-z_{t}\right) \odot h_{t}^{\prime}
$$

The GRU network was coded in Python. Figure 8 shows the pseudocode. To reproduce the results, the reader must have the data published by the French system operator for the last four years. The first three-year data are used for inputs of the network and the last-year data are employed as targets to train the network. It is of paramount importance to rescale all data to make them range between 0 and 1 to assure the network performance. The network parameters are set up by using the keras package. First of all, with the Sequential parameter, the code specifies that the model is sequential, and the output of each layer is the input for the next layer. In this study, the authors have used the Dropout function which is a technique where randomly selected neurons are ignored during training. This means that their contribution to the activation of downstream neurons is temporally removed on the forward pass and any weight updates are not applied to the neuron on the backward pass. The main advantage of this technique is that the network becomes less sensitive to the specific weights of neurons. The method used to analyze the error loss is the mean squared error which is widely recommended for regression problems. The method used to optimize the model is Adam which is an optimization algorithm that can be used instead of the classical stochastic gradient descent procedure to update network weights iteratively based on training data. It offers many advantages such as straightforward implementation and computational efficiency, among others. Other comments can be found in the pseudocode (Figure 8).

The algorithm estimates the structure generation for the next two hours (Figure 9) by using the data published by the French system operator $\left(\mathrm{CO}_{2}\right.$ generation structure and the total electricity demand of the day) and NAR networks. These networks are useful when handling time series and predictions. These networks have been created and trained in an open loop. In this case, the targets are used as feedback. Then, the networks are verified in a close loop [41-43,47]. Mathematically, NAR networks can be expressed by

$$
\hat{y}(t)=f(y(t-1)+y(t-2)+\ldots+y(t-d)+\varepsilon(t)
$$

where $f$ represents the network response taking into account the previous input data, and $\varepsilon(t)$ is the difference between the predicted value $\hat{y}(t)$ and the actual $y$. The number of delays establishes the $d$ values to be considered for the prediction. The number of hidden layers and neurons per layer is flexible to achieve the best performance of the neural network under design. This number must be carefully chosen to avoid an increase in the neural network complexity. The effect of choosing the value of the delay parameter is shown in Figure 10. As one can see, a high $d$ implies that the predicted line series line changes slower. On the other hand, when $d$ is lower, the predicted line series follows the real power wind value more accurately. However, if $d$ takes a very low value, then the predicted line series does not follow the real power wind value. The main explanation is that $d$ determines the weight given to past values. Consequently, significant changes in trend are not detected which could happen due to weather conditions. That is why, NAR networks are used in this research as an estimation and the accuracy remains on GRU networks. Anyway, this is not an issue as Matlab ${ }^{\circledR}$ allows correcting predictions if predicted values are known. This is the case of this application as it can predict $t+1$, $t+2, t+3 \ldots$ at a specific moment $t$. However, when the moment is $t+1$, the neural network can be updated as the predicted $t+1$ value and the real $t+1$ are known in real time (the French system operator publishes the needed data in real time). To reproduce the results of this study, the authors obtained good predictions for the next $2 \mathrm{~h}$ with $d=3$ when using the data belonging to 2019 published 
by the French system operator. The pseudocode of the NAR network is shown in Figure 11, coded by using Matlab ${ }^{\circledR}$ (Natick, MA, USA) The NAR networks were trained by using the trainlm function which implies that bias and weights are updated according to Levenberg-Marquardt optimization. It is the fastest backpropagation algorithm even if it may require more memory than other methods.

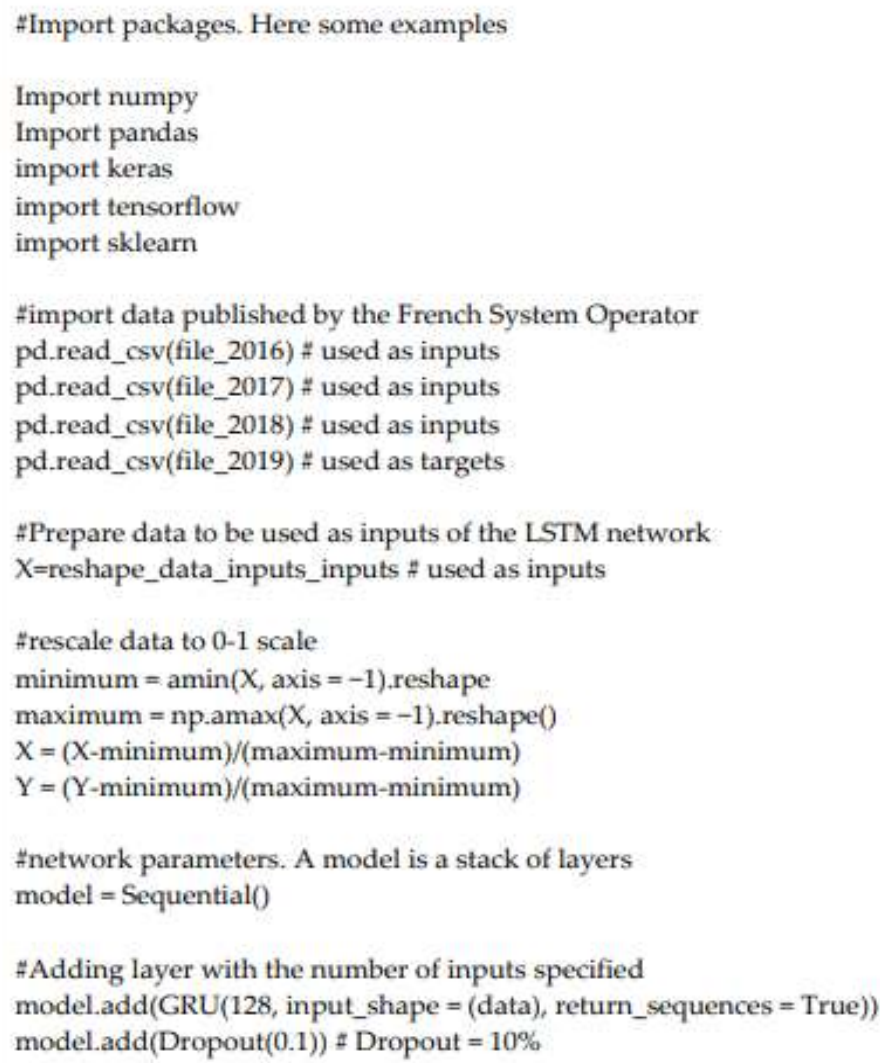

\# Boolean. Whether to return the last output in the output sequence, or the full sequence. model.add(GRU $(64$, return_sequences $=$ True $) *$ Adding layer with the number of inputs specified model .add $($ Dropout $(0.1)) \neq$ Dropout $=10 \%$

\# Boolean. Whether to return the last output in the output sequence, or the full sequence. model.add $(G R U(32$, return_sequences $=$ True $)))$ \#Adding layer with the number of inputs specified model.add $($ Dropout $(0.3)) \approx$ Dropout $=30 \%$

\#Optimizer choice and error measurement method model.compile(loss = 'mean_squared_error', optimizer = 'adam')

\#Training

his $=$ model.fit $(X, Y$, batch_size $=2$, nb_epoch $=5$, verbose $=1)$; , callbacks=[TQDMNotebookCallback 0$]$ )

\#Plot error

plt.legend("mean squared error", loc="upper left")

Figure 8. Pseudocode for the GRU networks. 


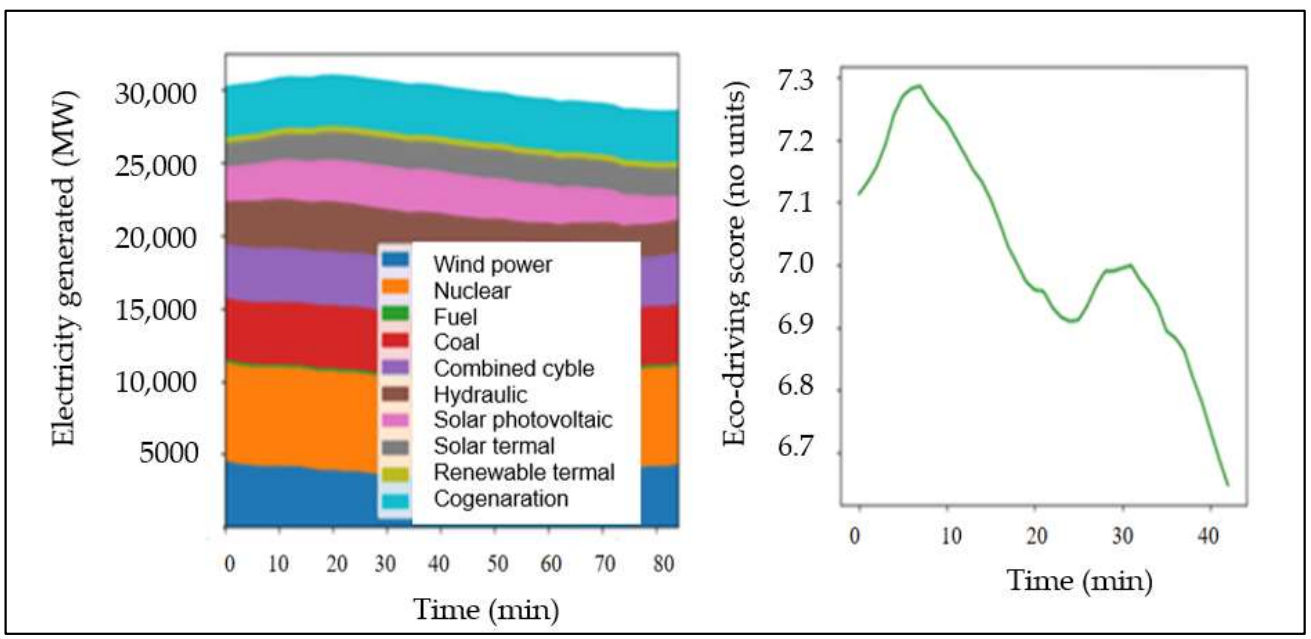

Figure 9. Interface of the application: eco-driving (EDR) and energy structure generation.

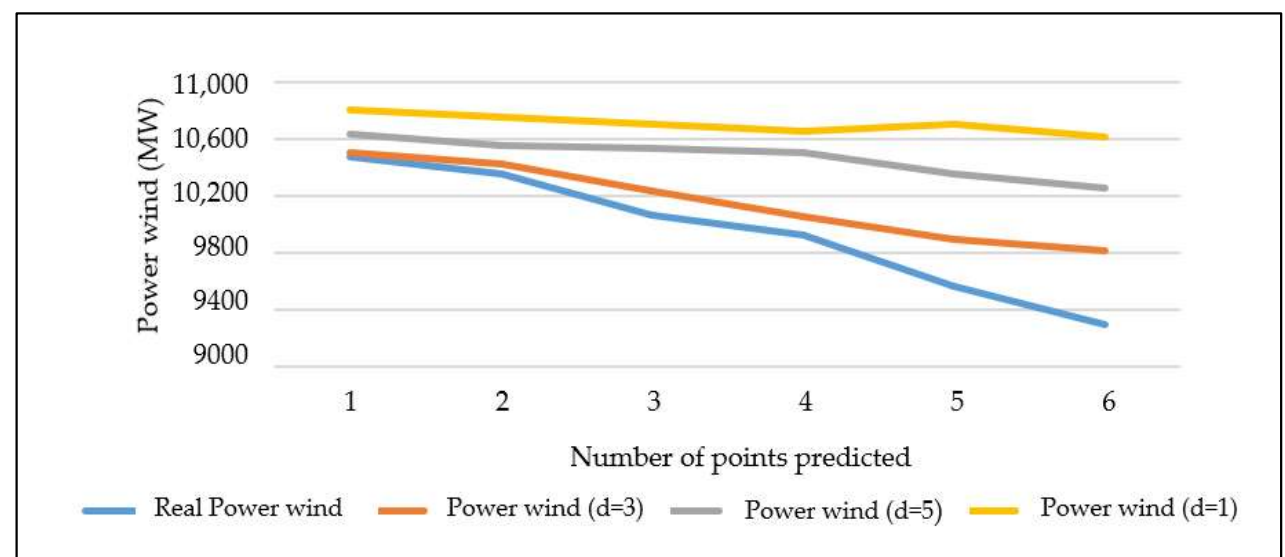

Figure 10. Prediction vs. real values depending on the delay parameter.

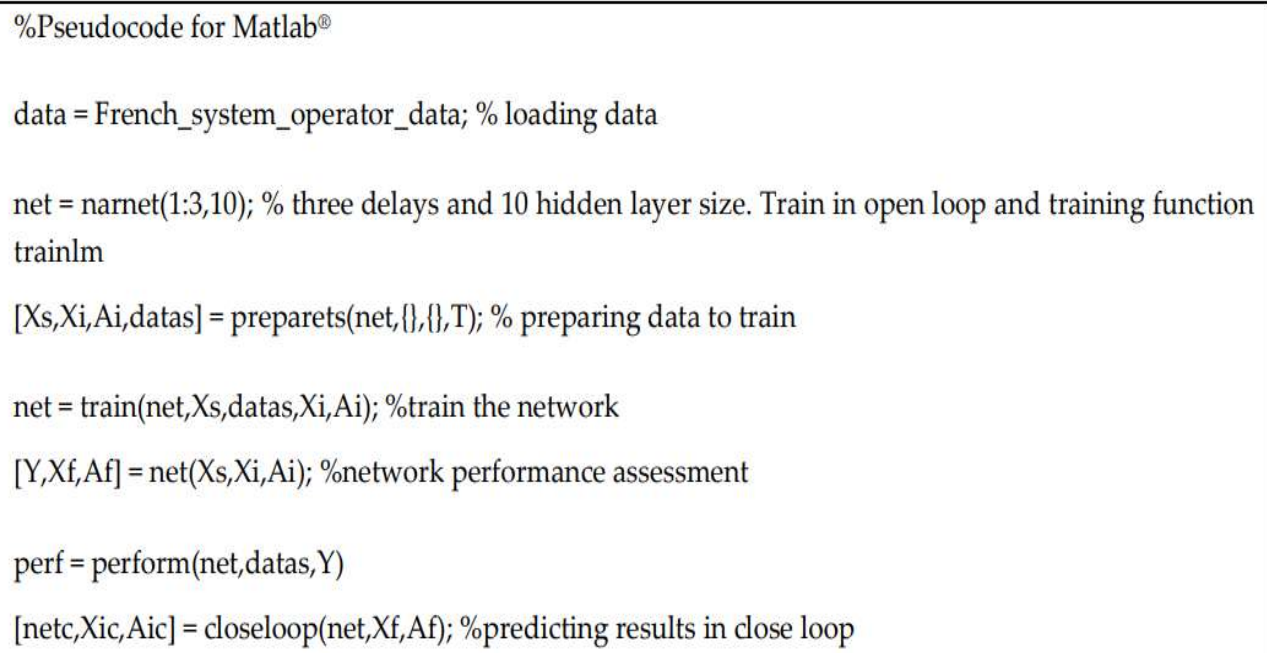

Figure 11. Pseudocode for nonlinear autoregressive (NAR) networks.

\subsection{Data Analysis}

As detailed in the result section, the data obtained in this research seem to be close to a normal distribution. Consequently, a method must be set to confirm this assumption. To do this, the package 
named PASSWR belonging to the R software was used. This package includes commands such as EDA which provide a lot of information to perform exploratory data analysis such as kurtosis, skewness and p-value. Kurtosis is a statistical measure that defines how heavily the tails of distribution differ from the tails of a normal distribution. Therefore, kurtosis identifies whether the tails of a given distribution contain extreme values. For a normal distribution, its value is 3 . There are three types of kurtosis: mesokurtic when kurtosis is close to 3; leptokurtic when values are quite higher than 3; and platykurtic when the extreme values are less than the normal distribution. Skewness essentially measures the symmetry of the distribution. For a normal distribution, its value should be close to 0 . At this point, it is important to highlight that symmetry does not imply that the data correspond to a normal distribution. Thus, these two parameters must be analyzed carefully. Finally, the p-value or probability value is the probability of obtaining test results at least as extreme as the results actually observed during the test, assuming that the null hypothesis is correct.

Plots are also of paramount importance when analyzing the data. In this research, three plots were used: histograms, Q-Q plots and boxplot. A histogram is a graphical representation which organizes a group of data points into user-specified ranges. The $\mathrm{Q}-\mathrm{Q}$ plot, or quartile-quartile plot, is a graphical tool used to assess if a set of data plausibly came from some theorical distribution such as a normal one. Finally, a box plot is a graphical rendition of statistical data based on the minimum, first quartile, median, third quartile and maximum. In this graph, the top of the rectangle indicates the third quartile, a horizontal line near the middle of the rectangle indicates the median and the bottom of the rectangle indicates the first quartile.

Figure 12 shows an example of how a dataset corresponds to a normal distribution by using PASSWR.

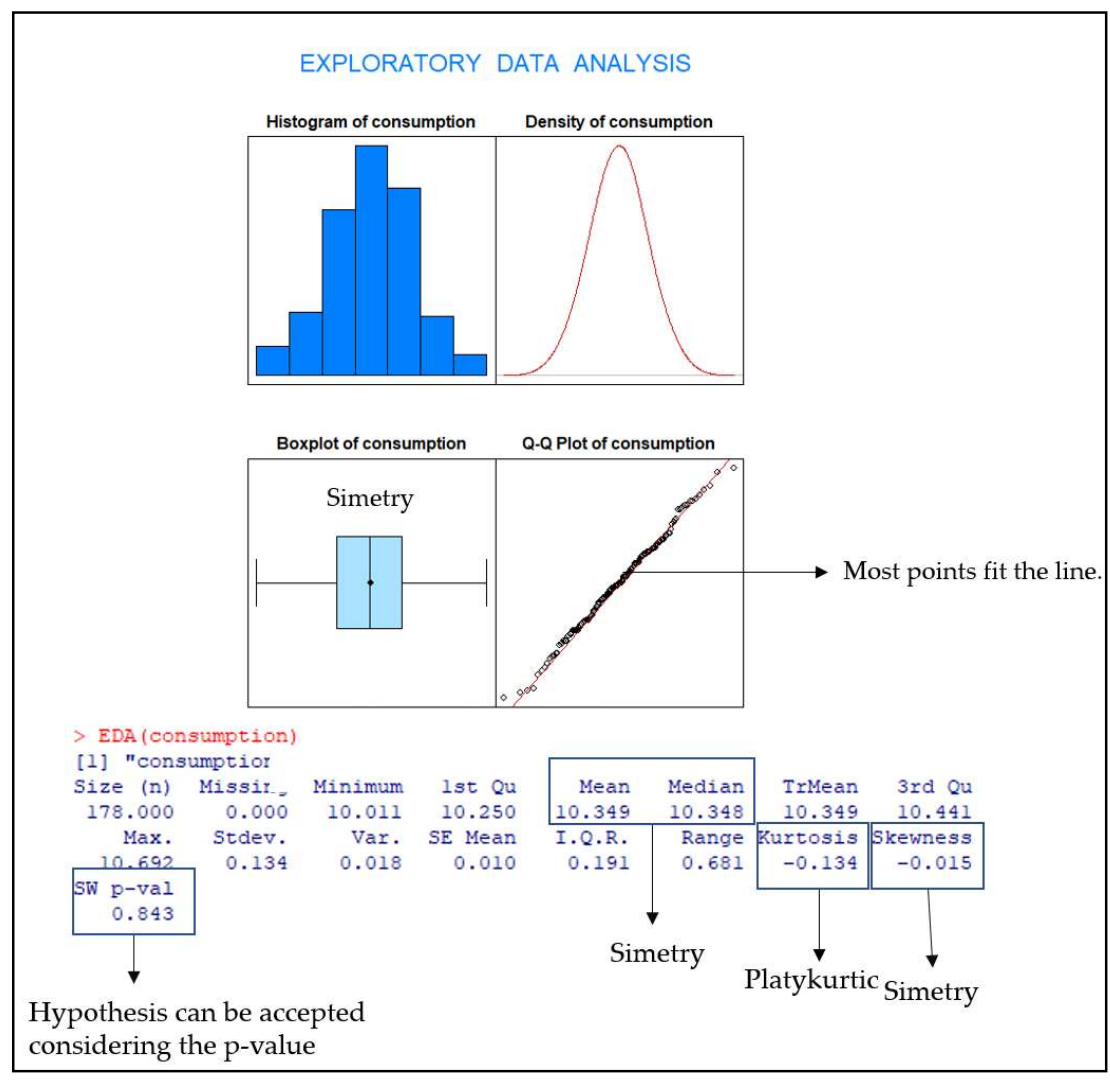

Figure 12. Example of the exploratory analysis performed in this research. 


\section{6. $V 2 G$}

The energy consumption of 5 buildings located in the design center and the contribution of V2G to reduce their energy consumption during product design were analyzed. Among the means that consume electricity in these buildings, one can find those that consume a great amount of energy such as test benches and, on the contrary, a considerable number of others such as computers, faxes and photocopying machines, which have much lower energy consumption. It is of paramount importance to assess the amount of energy that the EV can inject to reduce emissions and energy consumption during product design.

\subsection{Cybersecurity}

In this research, some data about the number of ECUs scrapped due to cybersecurity reasons will be shared. All these data are normalized considering the annual production (Section 3.4).

\section{Results}

This section is structured as follows. Section 3.1 shows the energy saving obtained when using EVs and the algorithm proposed in this research. This first analysis is of paramount importance because it allows assessing the amount of energy available for V2G. In addition, the trips from the design center to the factory are also discussed. Section 3.2 analyzes the energy consumption of the buildings located at the design center. The participation in V2G depends on energy policies. However, it must be highlighted that the charging process must be performed when the RE contribution is significant. Section 3.3 will also try to analyze that. Section 3.4 estimates waste due to ECU scrapped for cybersecurity reasons.

\subsection{Distribution of Engineers}

The project considered in this research deals with designing an ECU. As shown in Figure 2 and Table 1 , the reader can find the city and the location of all engineers participating in this project. Table 2 shows the statistical results achieved when processing the data obtained during the trips with no traffic jams. Without any traffic jams, the time needed to go from each location to the design center is very similar. Skewness is close to zero. Consequently, the distribution is symmetric. Kurtosis values show that the data distribution tails do not differ from normal distribution ones. The $p$-value represents the null hypothesis: the data follow a normal distribution. The null hypothesis can be considered as true if $\mathrm{p}$-value $>0.05$. Considering that the skewness and the kurtosis are sensitive to the sample size, the normality test was also confirmed by using $Q-Q$ plots and a histogram which confirmed the normal hypothesis.

Table 2. Statistics parameters obtained without any traffic jams.

\begin{tabular}{|c|c|c|c|c|c|c|c|c|c|c|}
\hline \multirow{2}{*}{ Factor } & \multicolumn{2}{|c|}{ Location A } & \multicolumn{2}{|c|}{ Location B } & \multicolumn{2}{|c|}{ Location C } & \multicolumn{2}{|c|}{ Location D } & \multicolumn{2}{|c|}{ Location E } \\
\hline & $\underset{\text { (1) }}{\text { N.A. }}$ & $\underset{\text { (2) }}{\text { A.U. }}$ & $\underset{\text { (1) }}{\text { N.A. }}$ & $\underset{\text { (2) }}{\text { A.U. }}$ & $\underset{\text { (1) }}{\text { N.A. }}$ & $\underset{\text { (2) }}{\text { A.U. }}$ & $\underset{\text { (1) }}{\text { N.A. }}$ & $\underset{\text { (2) }}{\text { A.U. }}$ & $\underset{\text { (1) }}{\text { N.A. }}$ & $\underset{\text { (2) }}{\text { A.U. }}$ \\
\hline Mean & 8.9 & 8.7 & 7.8 & 7.5 & 9.9 & 9.6 & 8.4 & 8.1 & 7.2 & 6.9 \\
\hline Std deviation & 0.2 & 0.15 & 0.18 & 0.15 & 0.16 & 0.12 & 0.19 & 0.15 & 0.16 & 0.12 \\
\hline Kurtosis & 3.9 & 4.1 & 3.7 & 4.5 & 4.1 & 4.2 & 4.1 & 3.9 & 4.1 & 4.3 \\
\hline Skewness & -0.135 & -0.121 & -0.041 & -0.032 & -0.025 & -0.015 & 0.035 & 0.03 & 0.08 & 0.045 \\
\hline$p$-value & 0.412 & 0.452 & 0.425 & 0.454 & 0.325 & 0.343 & 0.385 & 0.410 & 0.396 & 0.332 \\
\hline
\end{tabular}


Tables 3 and 4 show the statistical results achieved when processing the data obtained during the trips with traffic jams and mixed conditions. The way of interpreting the results is similar to Table 2. Q-Q plots and histogram confirm the assumptions.

Table 3. Statistics parameters obtained with traffic jams.

\begin{tabular}{ccccccccccc}
\hline \multirow{2}{*}{ Factor } & \multicolumn{2}{c}{ Location A } & \multicolumn{2}{c}{ Location B } & \multicolumn{2}{c}{ Location C } & \multicolumn{2}{c}{ Location D } & \multicolumn{2}{c}{ Location E } \\
\cline { 2 - 11 } & N.A. & $\begin{array}{c}\text { A.U. } \\
\text { (2) }\end{array}$ & $\begin{array}{c}\text { N.A. } \\
\text { (1) }\end{array}$ & $\begin{array}{c}\text { A.U. } \\
(\mathbf{2})\end{array}$ & $\begin{array}{c}\text { N.A. } \\
\mathbf{( 1 )}\end{array}$ & $\begin{array}{c}\text { A.U. } \\
(\mathbf{2})\end{array}$ & $\begin{array}{c}\text { N.A. } \\
\mathbf{( 1 )}\end{array}$ & $\begin{array}{c}\text { A.U. } \\
(\mathbf{2})\end{array}$ & $\begin{array}{c}\text { N.A. } \\
\mathbf{( 1 )}\end{array}$ & $\begin{array}{c}\text { A.U. } \\
(\mathbf{2})\end{array}$ \\
\hline Mean & 12.5 & 10.3 & 10.8 & 8.7 & 13.2 & 11.5 & 11.2 & 9.4 & 11.5 & 8.3 \\
\hline Std deviation & 0.9 & 0.89 & 0.98 & 0.95 & 0.75 & 0.81 & 0.99 & 0.88 & 1.15 & 1.01 \\
\hline Kurtosis & 3.2 & 3.4 & 3.15 & 3.35 & 3.25 & 3.45 & 3.185 & 3.36 & 3.15 & 3.58 \\
\hline Skewness & 0.281 & 0.112 & 0.231 & 0.189 & 0.261 & 0.185 & 0.259 & 0.189 & 0.262 & 0.215 \\
\hline$p$-value & 0.356 & 0.411 & 0.389 & 0.422 & 0.321 & 0.468 & 0.369 & 0.498 & 0.311 & 0.336 \\
\hline
\end{tabular}

(1) N.A. means no algorithm is used. ${ }^{(2)}$ A.U. means the algorithm is used.

Table 4. Statistics parameters obtained in mixed traffic conditions.

\begin{tabular}{|c|c|c|c|c|c|c|c|c|c|c|}
\hline \multirow{2}{*}{ Factor } & \multicolumn{2}{|c|}{ Location A } & \multicolumn{2}{|c|}{ Location B } & \multicolumn{2}{|c|}{ Location C } & \multicolumn{2}{|c|}{ Location D } & \multicolumn{2}{|c|}{ Location E } \\
\hline & N.A. ${ }^{(1)}$ & $\underset{\text { (2) }}{\text { A.U. }}$ & $\underset{\text { (1) }}{\text { N.A. }}$ & $\underset{(2)}{\text { A.U. }}$ & $\underset{\text { (1) }}{\text { N.A. }}$ & $\underset{\text { (2) }}{\text { A.U. }}$ & $\underset{\text { (1) }}{\text { N.A. }}$ & $\underset{\text { (2) }}{\text { A.U. }}$ & $\underset{\text { (1) }}{\text { N.A. }}$ & $\underset{\text { (2) }}{\text { A.U. }}$ \\
\hline Mean & 10.8 & 9.2 & 9.5 & 8.1 & 12.1 & 10.5 & 10.6 & 8.8 & 10.1 & 7.5 \\
\hline Std deviation & 0.6 & 0.5 & 0.9 & 0.6 & 0.75 & 0.65 & 0.85 & 0.5 & 0.65 & 0.58 \\
\hline Kurtosis & 3.5 & 3.7 & 3.45 & 3.98 & 3.8 & 3.9 & 3.68 & 3.56 & 3.98 & 3.99 \\
\hline Skewness & 0.145 & -0.081 & 0.158 & 0.148 & 0.225 & 0.118 & 2.435 & 0.195 & 2.72 & 0.238 \\
\hline$p$-value & 0.359 & 0.401 & 0.256 & 0.385 & 0.458 & 0.453 & 0.399 & 0.401 & 0.358 & 0.367 \\
\hline
\end{tabular}

\subsection{Building Energy Consumption}

The design center is composed of five buildings with different configurations. Table 5 shows the characteristics of each building. These items were chosen after having analyzed the energy consumption data provided by the company participating in this research. Only the most highly energy-consuming items were considered.

Table 5. Characteristics of buildings.

\begin{tabular}{|c|c|c|c|c|c|}
\hline & Building 1 & Building 2 & Building 3 & Building 4 & Building 5 \\
\hline Number of floors & 1 & 1 & 1 & 2 & 2 \\
\hline $\begin{array}{c}\text { Number of } \\
\text { meeting rooms }\end{array}$ & 2 & 4 & 3 & 8 & 12 \\
\hline Number of offices & 10 & 12 & 10 & 20 & 40 \\
\hline $\begin{array}{l}\text { Type of heating } \\
\text { system }\end{array}$ & Electric & Electric & Electric & Electric & Electric \\
\hline Lighting & $\begin{array}{c}\text { Fluorescent } \\
\text { low-power energy } \\
\text { consumption } \\
\text { lighting system }\end{array}$ & $\begin{array}{c}\text { Fluorescent } \\
\text { low-power energy } \\
\text { consumption } \\
\text { lighting system }\end{array}$ & $\begin{array}{c}\text { Fluorescent } \\
\text { low-power energy } \\
\text { consumption } \\
\text { lighting system }\end{array}$ & $\begin{array}{c}\text { Fluorescent } \\
\text { low-power energy } \\
\text { consumption } \\
\text { lighting system }\end{array}$ & $\begin{array}{c}\text { Fluorescent } \\
\text { low-power energy } \\
\text { consumption } \\
\text { lighting system }\end{array}$ \\
\hline
\end{tabular}


Figure 13 depicts the energy consumption for each building. These values were obtained by using electric meters installed in the design center, the number of hours of operation considering timetables and average energy consumption of facilities/items. The main differences between these buildings were the number of people working, which affects the number of other elements present in the buildings such as printers, and the presence of laboratories.

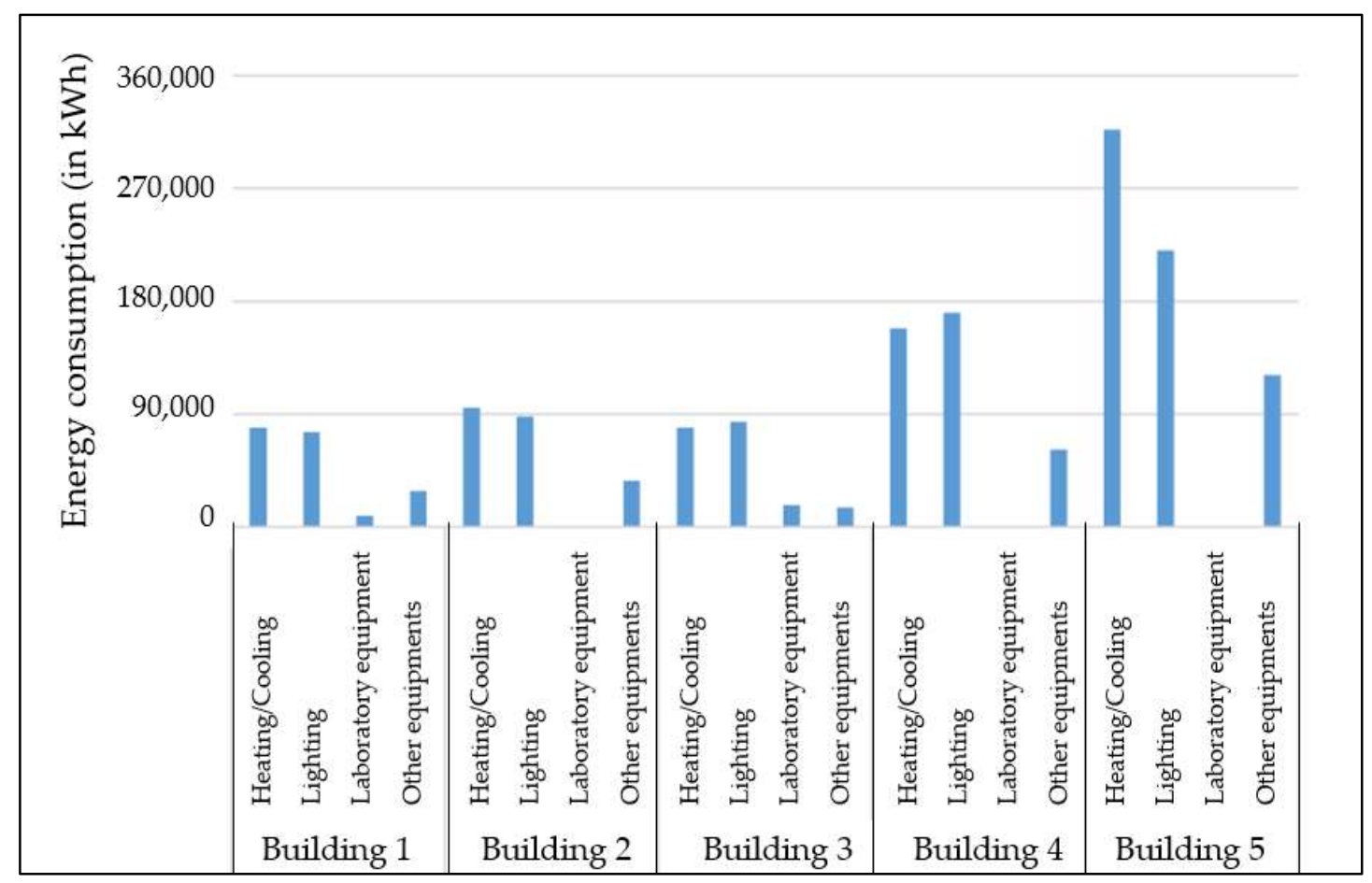

Figure 13. Energy consumption of each building.

Considering the results shown in Tables 2-4, the energy to be used for V2G technology is assessed. However, V2G must be also compatible with V2H technology. Logically, the drivers will be willing to save this available energy for their own homes rather than injecting it into the grid. This topic will be discussed in the result discussion in Section 4.3.

Table 6 depicts the main results obtained in this research. An additional gain of $2.89 \%$ to V2G can be obtained when considering mixed traffic conditions (with and without traffic jams). This percentage can be increased by $6.9 \%$ considering the influence of traffic jams. This percentage was obtained by dividing the total energy available per day when using and not using the algorithm

Table 6. Summary of energy saving.

\begin{tabular}{ccccccc}
\hline Title Traffic & $\begin{array}{c}\text { Total Energy } \\
\text { Consumption } \\
\text { (in kWh) }\end{array}$ & $\begin{array}{c}\text { Total Energy } \\
\text { Available } \\
\text { When Using } \\
\text { the } \\
\text { Algorithm Per } \\
\text { Day in } \mathbf{k W h}\end{array}$ & $\begin{array}{c}\text { Total Energy } \\
\text { Available } \\
\text { without } \\
\text { Using the } \\
\text { Algorithm Per } \\
\text { Day in kWh }\end{array}$ & $\begin{array}{c}\text { Contribution to } \\
\text { Meet Energy } \\
\text { Consumption } \\
\text { When Using } \\
\text { the Algorithm } \\
\text { (in \%) }\end{array}$ & $\begin{array}{c}\text { Contribution to } \\
\text { Meet Energy } \\
\text { Consumption } \\
\text { without Using } \\
\text { the Algorithm } \\
\text { (in \%) }\end{array}$ & $\begin{array}{c}\text { Delta Per Day } \\
\text { without } \\
\text { Using the } \\
\text { Algorithm } \\
\text { (in kWh) }\end{array}$ \\
$\begin{array}{c}\text { Delta Per Year } \\
\text { When Using } \\
\text { the Algorithm } \\
\text { (in kWh) }\end{array}$ \\
\hline $\begin{array}{c}\text { Without traffic } \\
\text { jams }\end{array}$ & 7540.1 & 1397.6 & 1384.4 & 18.5 & 18.4 & 13.2 \\
\hline $\begin{array}{c}\text { With traffic } \\
\text { jams }\end{array}$ & 7540.1 & 1332.8 & 1239.6 & 17.7 & 16.4 & 2904 \\
\hline $\begin{array}{c}\text { Mix with and } \\
\text { without traffic } \\
\text { jams }\end{array}$ & 7540.1 & 1376.9 & 1337.1 & 18.3 & 17.7 & 39.8 \\
\hline
\end{tabular}




\subsection{RE Contribution to Charge EVs}

The EVs belonging to employees should inject power into the grid when electricity consumption peaks take place. Generally, every day there are two peaks of electricity consumption which depend on the season and on the day of the week (Figure 14). Anyway, these peaks usually occur between 8 a.m. and 1:30 p.m. and from 5:30 p.m. to 8 p.m. In this research, power should be injected to reduce the first electricity consumption peak. The fact of injecting this power into the grid from EVs implies that EVs should be recharged in some cases by the user to have enough energy to come back home. Consequently, it is of paramount importance to charge them when REs are being used. In other words, the recharge process should be done when the mix is greener. The algorithm proposed by the authors allows determining when the RE contribution is higher by using Equations (1) and (2). Therefore, the charging process is greener.

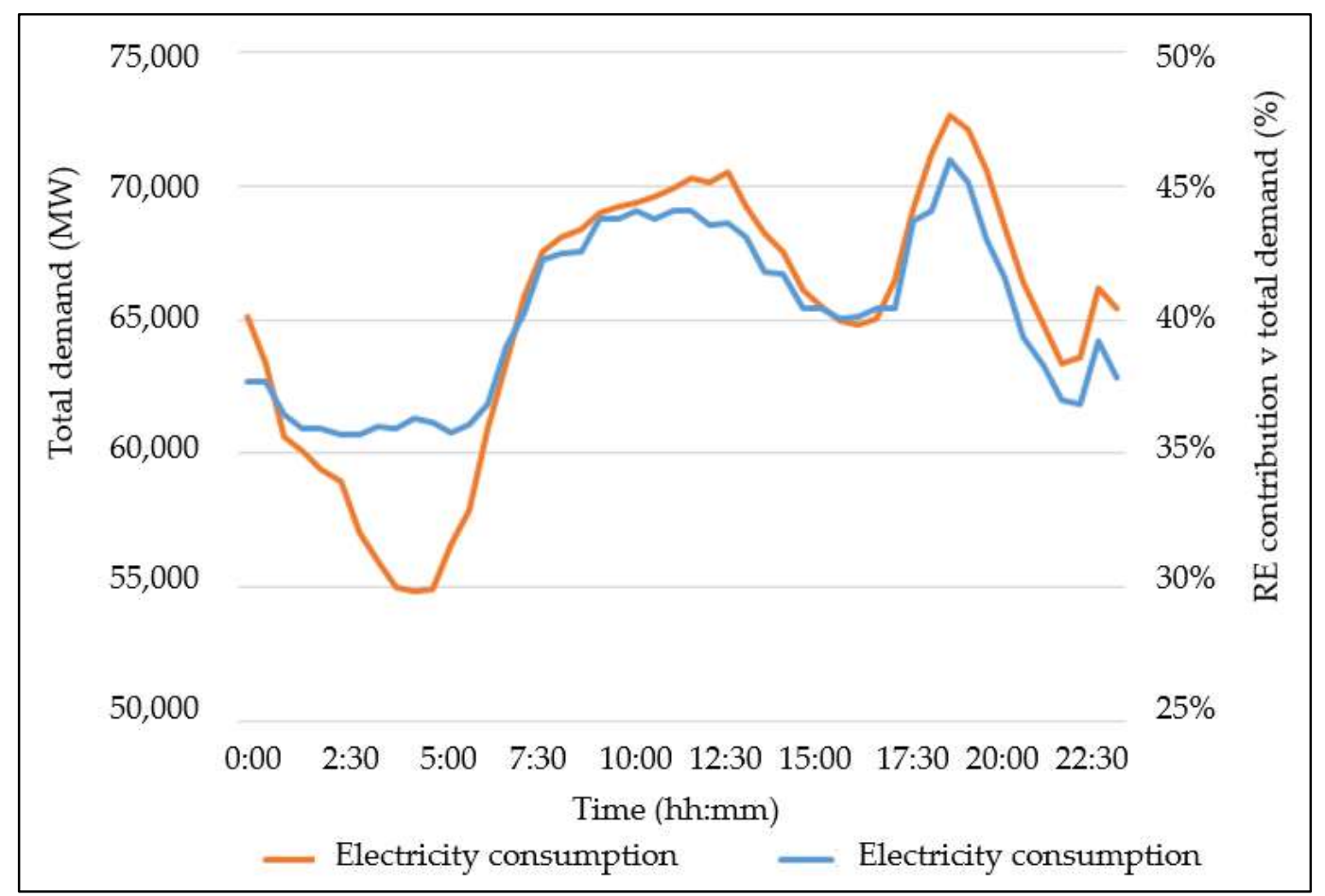

Figure 14. Renewable energy (RE) contribution for January 2018. Source: French system operator.

Table 7 shows the electricity prices offered by different suppliers in France.

Table 7. Electricity prices.

\begin{tabular}{ccc}
\hline Supplier & $\begin{array}{c}\text { Price for Off-Peak Periods } \\
\text { (EUR/kWh) }\end{array}$ & $\begin{array}{c}\text { Price for Peak Periods } \\
\text { (EUR/kWh) }\end{array}$ \\
\hline Supplier 1 & 0.1230 & 0.1580 \\
\hline Supplier 2 & 0.1272 & 0.1638 \\
\hline Supplier 3 & 0.1280 & 0.1660 \\
\hline Supplier 4 & 0.1161 & 0.1483 \\
\hline Supplier 5 & 0.1138 & 0.1453 \\
\hline Supplier 6 & 0.1180 & 0.1513 \\
\hline
\end{tabular}

Considering the prices shown in Table 7 and Figure 14, several conclusions can be drawn: Firstly, when the RE contribution is high, charging the EV battery is expensive, and the other way around. 
Secondly, drivers participating in V2G and V2H should charge their EVs between off-peak periods. Consequently, rapid or fast charging should be used. Consequently, battery life is reduced. Finally, the RE contribution vs. traditional energy sources during off-peak periods must be increased.

Policies should change to increase the RE contribution when charging EVs especially during off-peak periods. The French government announced a new plan to increase the usage of RE. This plan has new different objectives for 2023. In this new plan, two scenarios are unfolded: an optimistic and a pessimistic one. The most important figures imply that the total power installed should reach 69,980 MW in the worst-case scenario and 76,743 MW in the optimistic one. In addition to this, 150 and 167 TWh renewably sourced electricity should be delivered, respectively. It must be reminded that the current renewable capacity in France is close to 56,000 MW. Some important figures to be retained [48]:

- Primary energy consumption by RE: $10.7 \%$;

- Gross electricity production by ER in 2017: 92.6 TWh.

\subsection{Cybersecurity}

As aforementioned in the previous sections, cybersecurity could involve a considerable amount of waste to be considered. Table 8 shows the results of this research considering 120,000 ECUs in series production and 1200 prototype units per year. Firstly, the reader can see the number of ECUs scrapped for one year due to cybersecurity reasons. The percentage of scrapped ECUs when producing prototype ECUs reaches $10.83 \%$. Secondly, ECUs are mainly composed of plastic (housings) and electronic wastes such as microprocessors, resistors, etc. The components used in these ECUs are confidential. In addition to the data depicted in Table 8, other factors must be considered such as: varnish used in the manufacturing process, energy needed to weld and logistic transportation (emissions), among others. It must be remarked that prototype parts have a high scrap rate. Consequently, the waste produced during projects should also be considered in eco-design.

Table 8. Electronic control units (ECUs) scrapped due to cybersecurity.

\begin{tabular}{|c|c|c|c|c|}
\hline Component & Quantity & $\begin{array}{c}\text { Series } \\
\text { Production }\end{array}$ & Quantity & $\begin{array}{l}\text { Prototype } \\
\text { Production }\end{array}$ \\
\hline Microprocessors & 190 & \multirow{8}{*}{$0.16 \%$} & 130 & \multirow{8}{*}{$10.83 \%$} \\
\hline Printed circuit board & 190 & & 130 & \\
\hline Housing & 380 & & 260 & \\
\hline Capacitors & 17,100 & & 11,700 & \\
\hline Resistors & 21,100 & & 14,436 & \\
\hline Programmable components & 190 & & 130 & \\
\hline Input/output connectors & 190 & & 130 & \\
\hline Memory RAM & 280 & & 260 & \\
\hline
\end{tabular}

\section{Discussion}

This section discusses the results obtained in this research. Section 4.1 analyzes the algorithm when it comes to sustainability. Section 4.2 describes how the energy efficiency is improved. Section 4.3 explores the RE contribution. Section 4.4 discusses the number of engineers chosen for this study. Section 4.5 entitled "threats to the validity", analyzes the main factors which could have an influence on the results obtained in this research.

\subsection{Sustainability of This Solution}

No matter what kind of powertrain is used in a vehicle (hybrid, electric, diesel or gasoline), $\mathrm{CO}_{2}$ emissions are always present as analyzed by the International Council on Clean Transportation [49]. As shown in Figure 15, EVs pollute less than conventional vehicles when it comes to life-cycle emissions. Therefore, the algorithm and the solution proposed in this research are sustainable despite the process of charging and discharging that harms the battery. In addition, the EVs increase is confirmed by such 
a supplier as Continental ${ }^{\circledR}$, considering the latest news concerning the recent sale of its diesel and petrol powertrain unit. Thermic engine activities are supposed to be reduced while EV activities are most likely to be increased in the year to come.



Figure 15. Life-cycle emissions from electric and conventional vehicles. Source: The International Council on Clean Transportation.

\subsection{Energy Efficiency Improvement}

Several policies are pursued with the aim of improving energy consumption based on increasing the RE usage, eco-design and building energy consumption. When it comes to eco-design, energy efficiency is a key factor and engineers try to improve energy consumption during the manufacturing process. When it comes to design processes, the eco-design process is mainly focused on the usage of recyclable raw materials and on the design of products that do not pollute much during their lives and they can also be recycled easily at the end of their lives. This research shows that the design process involves many factors that should be considered as they generate emissions in a significant way. Unfortunately, the eco-design directive does not include many topics that clearly have an influence on emissions during the design process. Investments in $\mathrm{V} 2 \mathrm{G}$ technology allow reducing energy consumption during the design process. This reduction is increased when using the algorithm proposed in this study without any additional investment.

Several conclusions can be drawn from the data depicted in Table 5. V2G plays an essential role when it comes to eco-design as a range between 2904 and 20,504 kWh more per year is available when using depending on traffic conditions. In other words, the reduction ranges from 13.2 to $93.2 \mathrm{kWh}$ per day. This figure could be increased by $61.52 \mathrm{kWh}$ in mixed traffic conditions as detailed in Section 4.4. These results were obtained when using only 44 engineers.

The energy efficiency improvement allows reducing emissions. As depicted in Table 9, the emission reduction ranging from 8.96 to $23.55 \mathrm{~kg}$ per day was obtained when using the algorithm proposed in this study. These values were obtained taking into account the energy saving (in $\mathrm{kWh}$ ) and the monthly emission average from January to July 2019. It must be remarked that only 44 engineers participated in this study. 
Table 9. Emissions of $\mathrm{CO}_{2}$ (in $\mathrm{g} / \mathrm{kWh}$ ) on a monthly basis. Source: French system operator.

\begin{tabular}{cccccccc}
\hline Title Emissions & January & February & March & April & May & June & July \\
\hline Emissions $(\mathrm{g} / \mathrm{kWh})$ & 55.68 & 51.30 & 31.24 & 26.32 & 24.74 & 27.65 & 35.85 \\
\hline $\begin{array}{c}\text { Emission reduction per day } \\
(\mathrm{kg} / \mathrm{kWh}) . \text { Mixed traffic }\end{array}$ & 2.22 & 2.04 & 1.24 & 1.05 & 0.98 & 1.1 & 1.43 \\
\hline $\begin{array}{c}\text { Emission reduction per day } \\
(\mathrm{kg} / \mathrm{kWh}) . \text { No traffic jams }\end{array}$ & 5.19 & 4.78 & 2.91 & 2.45 & 2.31 & 2.57 & 3.34 \\
\hline
\end{tabular}

Finally, the fact of reducing energy consumption by using V2G is a topic which has been subjected to research. The contribution may be significant when the smart grid will be fully deployed. However, it should be also considered that V2G must be compatible with V2H. As shown in this research, it is not always the case. Several axes are essential to make them work together. The first one is improving battery capacities in such a way that the owner can use the energy stored in the battery for both purposes (V2H and V2G). The second one is also linked to batteries as the fact of going through charging and discharging processes should not degrade batteries quickly. Finally, the RE contribution must be increased as described in Section 3.3.

\subsection{Renewable Energies}

From a theoretical point of view, it is vital to consider V2G technology to reduce the energy consumption of design buildings. In this case, two factors must be discussed. The first one is EV penetration into the market. The second one is policies. The former is essential due to the fact that the more EVs are sold, the more energy is available for V2G. Policies try to encourage drivers to choose EVs instead of traditional powertrains such as gasoline or diesel engines. Among these measures, one can find exemption from vehicle registration duties or municipal tax discounts. Despite this, the participation in $\mathrm{V} 2 \mathrm{G}$ remains unclear for several reasons:

(a) Drivers who cover many kilometers on a daily basis will be forced to choose between V2G and $\mathrm{V} 2 \mathrm{H}$ techniques. Considering that if drivers inject energy during the day to reduce the energy consumption in buildings, they will probably need to charge as soon as they get to their homes. Consequently, they cannot participate in $\mathrm{V} 2 \mathrm{H}$;

(b) The fact of reducing prices to make drivers charge their vehicles after 2 p.m. is still far from being the solution as the RE contribution is not substantial. Therefore, it is essential to promote RE facilities.

The algorithm proposed in this research allows choosing the best moment to charge the EV battery considering the electricity mix. Considering all the aforementioned facts, V2G can contribute in a significant way to the reduction of emissions during the design process and should be also a key element to be considered in eco-design. However, the percentage of improvement is completely linked to policies associated with EV recharging.

\subsection{Population Participating in This Study}

Several factors must be considered when it comes to the population participating in this research. Firstly, this research was conducted considering a small size research and development center. It must be taken into account that there are much bigger design centers in France such as the one of Renault located in Lardy (1600 workers) or the one of PSA Peugeot-Citroen located in Carrières-sous-Poissy (1300 workers). Therefore, the number of engineers who can participate when implementing the algorithm will increase. However, policies are still important to encourage people to participate in V2G $[33,50]$.

Figure 16 shows an estimate when choosing a greater number of engineers (400 engineers) and the energy consumption calculated in Section 3.1, and the assumption shown in Table 10. When it 
comes to the number of engineers, the values were assigned by respecting the percentage of engineers of each location established for the test-case. When it comes to the number of times with and without traffic jams, these values were considered for the whole year. In addition, an error estimate has been added, which represents the nominal estimate with a $20 \%$ error, $30 \%$ error and so on (Table 11).



Figure 16. Energy available depending on the error in energy consumption estimate when using 400 engineers.

Table 10. Assumptions when considering a greater number of engineers.

\begin{tabular}{ccc}
\hline Title Locations & Number of Engineers & Number of Times without and with Traffic Jams \\
\hline Location A & 91 & $300 / 60$ \\
\hline Location B & 73 & $320 / 40$ \\
\hline Location C & 73 & $316 / 44$ \\
\hline Location D & 109 & $180 / 120$ \\
\hline Location E & 54 & $170 / 140$ \\
\hline
\end{tabular}

Table 11. Gain when considering a greater number of engineers.

\begin{tabular}{|c|c|c|c|c|c|c|c|}
\hline $\begin{array}{c}\text { Title Energy and Gain } \\
\text { Obtained }\end{array}$ & $20 \%$ Error & $30 \%$ Error & $40 \%$ Error & $50 \%$ Error & $60 \%$ Error & $70 \%$ Error & $80 \%$ Error \\
\hline Energy available per year & 81,824 & 71,596 & 61,368 & 51,140 & 40,912 & 30,684 & 20,456 \\
\hline Energy available per day & 371.93 & 325.44 & 278.95 & 232.45 & 185.96 & 139.47 & 92.98 \\
\hline $\begin{array}{c}\text { Gain per day in EUR } \\
(0.1347 \text { EUR/kWh })\end{array}$ & 50.09 & 43.84 & 37.57 & 31.31 & 25.05 & 18.79 & 12.52 \\
\hline $\begin{array}{c}\text { Gain per year } \\
\text { (220 working days) }\end{array}$ & 11,021 & 9643.98 & 8266.26 & 6888.55 & 5510.84 & 4133.13 & 2755.42 \\
\hline
\end{tabular}

Figure 16 represents the increase in energy available for V2G when using the algorithm. Location $\mathrm{D}$ and Location $\mathrm{E}$ outperform the rest of the locations when it comes to energy savings. The number of engineers (in other words the number of EVs) is not only the most relevant parameter to obtain more or less contribution to V2G and eco-design as Location $\mathrm{E}$ is the one which has fewer engineers/EVs participating in this case-study. Consequently, location is an important parameter.

Another important topic to be discussed is that this algorithm does not require investing in new facilities. Once the design center is adapted to use V2G, no more action is needed except for using this 
algorithm. As shown in Table 11, the fact of using it implies that an extra gain by EUR 11,021 could be obtained in this authors' estimate. Table 11 also shows the gain (difference between the energy available when using and not using the algorithm).

When considering the number of engineers participating in this case-study, the results are similar (Figure 17). Again, location D and E account for the biggest amount of energy available for V2G. Consequently, the V2G energy value does not only depend on the number of EVs (engineers) participating in this research but the location of the engineers.

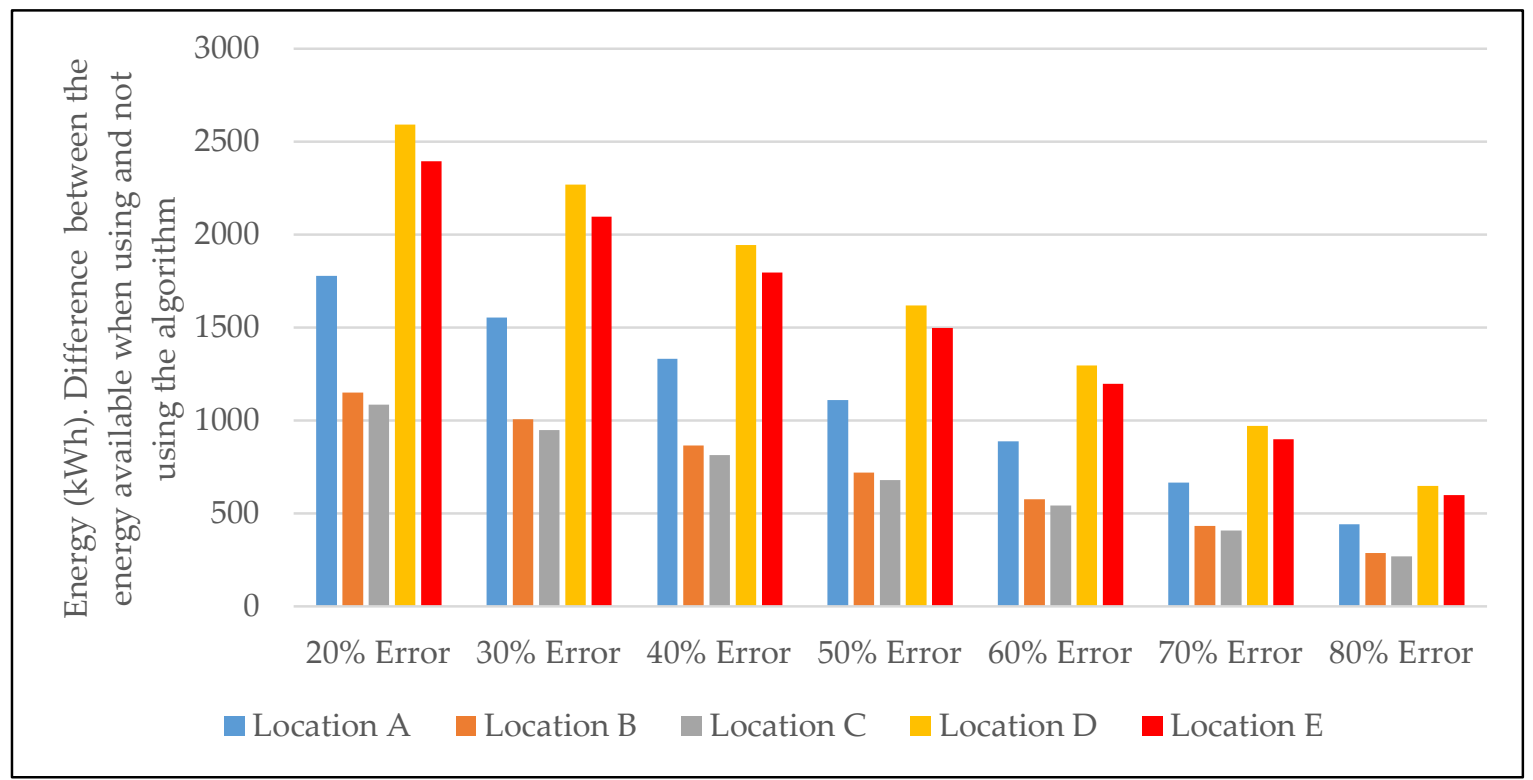

Figure 17. Energy available depending on the error in the energy consumption estimate when using 44 engineers.

Choosing the optimal location is of paramount importance. If $22 \mathrm{EVs}$ had been assigned to Location D and E respectively (Figure 18), the energy available for V2G would have been increased from 39.8 to $61.52 \mathrm{kWh}$ per day.

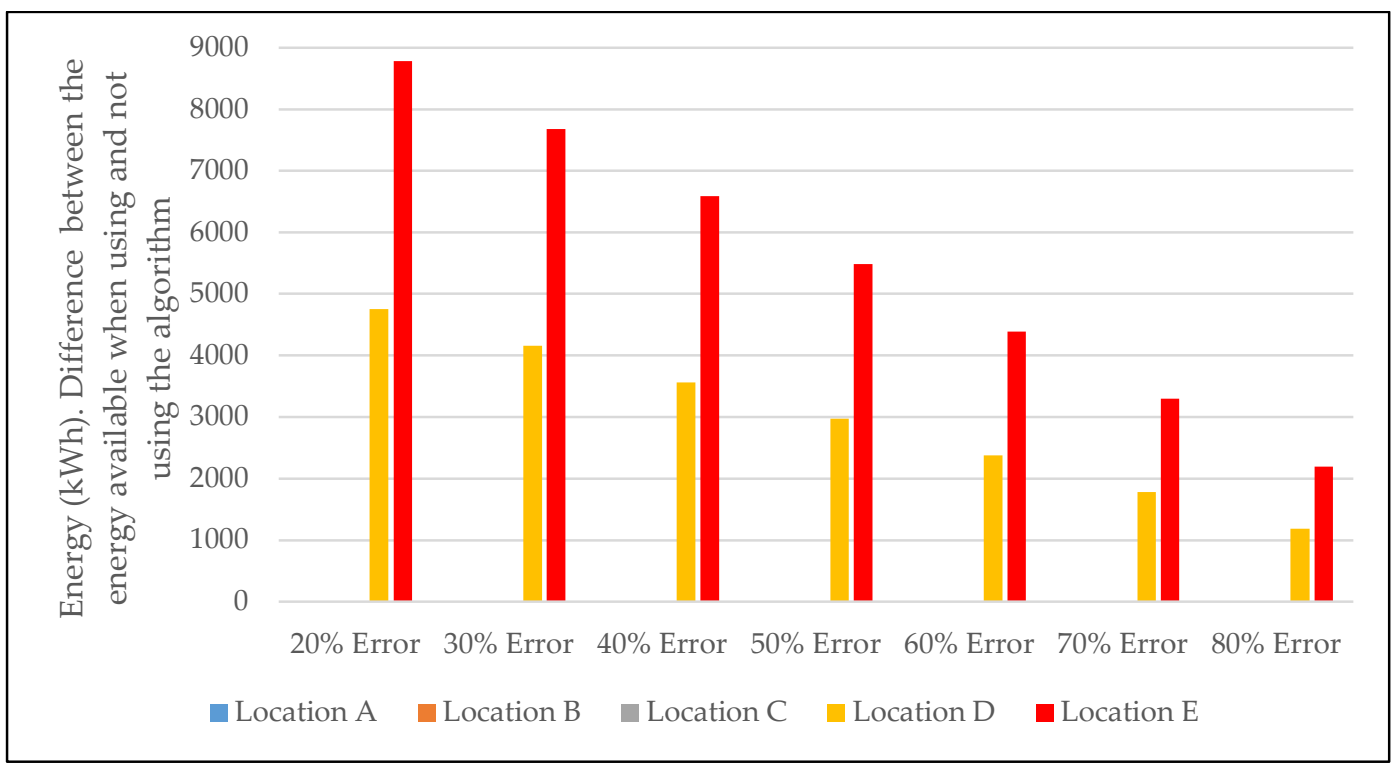

Figure 18. Energy available depending on the error in the energy consumption estimate when using 44 engineers only for destinations $\mathrm{D}$ and $\mathrm{E}$. 
Several factors such as distance and traffic state among others determine the optimal location to optimize the V2G contribution. Therefore, models which can predict the V2G contribution when determining the optimal number of engineers and location must be developed, as the fact of using more EVs does not imply that the contribution to V2G has increased in a significant way. This algorithm can be used offline to determine the optimal locations by following the procedure shown in Figure 19. Here ${ }^{\circledR}$ API can assess the routes offline to obtain the time needed and, consequently, the EV energy consumption. Thanks to this procedure, the energy consumption estimate for each driver can be obtained and, consequently, the optimal locations can be chosen.



Figure 19. Method to choose the optimal locations.

\subsection{Threats to Validity}

In this research, internal and external threats have been analyzed. Table 12 depicts the main variables to be controlled (predictors) to check the influence on the response variables. Even though the authors considered that factors 1, 2 and 3 were chosen properly to obtain fully representative results, it is obvious that all these factors could reduce the energy available for V2G. Therefore, the energy consumption of the buildings belonging to the design center which can be supported by V2G, could be decreased. Table 12 also describes the mitigation plan (description column) to justify that the results of this research are well founded.

Table 12. Factors to be controlled in this research.

\begin{tabular}{|c|c|c|}
\hline Id Factor & Factor & Description \\
\hline 1 & $\begin{array}{l}\text { Sample used in this research } \\
\text { to validate the hypothesis }\end{array}$ & $\begin{array}{l}\text { The number of engineers considered to assess the energy available for } \\
\text { V2G in this research. The authors considered that this figure is } \\
\text { significant enough as it accounts for } 45 \% \text { of the total number of the } \\
\text { engineers who work in the design center. }\end{array}$ \\
\hline 2 & Distribution of locations & $\begin{array}{l}\text { Locations of engineers' homes. The authors consider that their locations } \\
\text { are optimal as they are situated in all possible directions around the city } \\
\text { (north, south, east and west) }\end{array}$ \\
\hline 3 & $\begin{array}{l}\text { Season considered in this } \\
\text { research }\end{array}$ & $\begin{array}{l}\text { This research was conducted during the winter, the spring and the } \\
\text { summer. Consequently, the battery operated in cold and hot } \\
\text { temperatures to calculate the number of kWh available for V2G. }\end{array}$ \\
\hline 4 & Energy available for V2G & Energy available in the EV battery to be used for V2G. \\
\hline 5 & GRU estimate & $\begin{array}{l}\text { Every time a GRU neural network is built to predict a time series, a } \\
\text { performance assessment of the network is carried out. The process is } \\
\text { done by using Python. As shown in Figure } 20 \text {, the performance } \\
\text { assessment values were good enough to use the network ( } 8 \mathrm{E}-07 \text { the } \\
\text { worst case). When it comes to NAR networks, they are automatically } \\
\text { built by using Matlab }{ }^{\circledR} \text {. }\end{array}$ \\
\hline
\end{tabular}






Figure 20. GRU performance evaluation.

When it comes to external variables, the authors consider that the main conclusions of this paper can be applied to other cities or design centers as:

(a) No matter how much energy is accumulated in vehicles, this energy can be used, and it can contribute to the reduction of energy consumption by buildings of design centers;

(b) $\mathrm{V} 2 \mathrm{H}$ and $\mathrm{V} 2 \mathrm{G}$ techniques are most unlikely to be compatible when EV energy consumption is high.

During this research, every day when the trips were going to be taken, the following tasks were carried out:

(a) New GRU and NAR networks were implemented considering the data published by the French system operator the day before;

(b) The predicted results by the GRU and NAR neural networks were compared with the results published by the French system operator considering the periods of the day when the trips were made. Figure 18 shows the performance of the GRU neural network obtained when it was implemented on a daily basis.

The aim of this procedure was to assure that the neural networks worked as expected.

\section{Conclusions}

Eco-design deals with several topics such as low-impact materials, energy efficiency, design for reuse and recycle, sustainable design standards and renewable energy, among others. However, energy efficiency should not only deal with manufacturing but the product design phase. This research is focused on how electric vehicles (EVs), vehicle-to-grid (V2G), eco-driving, eco-routing and eco-charging can contribute to energy savings during product design. Therefore, these factors play an essential role in eco-design. Taking into account the method and results obtained in this research, the following conclusions are drawn:

(a) Energy savings The algorithm proposed in this research which uses energy consumption models properly tuned for eco-driving, eco-routing and eco-charging allows reducing energy consumption between $2.89 \%$ and $6.9 \%$ as proved in Section 3.2. In addition to this reduction, neural networks provide drivers with useful information about when the optimal moment is to charge the battery, taking into account the renewable energy contribution. 
(b) Eco-design This algorithm contributes to eco-design as:

(b.1) It allows reducing emissions between 8.96 and $23.55 \mathrm{~kg}$ per day (Section 4.2) of $\mathrm{CO}_{2}$ more than when EVs do not use the algorithm in this study;

(b.2) This research shows that not only the number of EVs is important to increase the energy available but the way of choosing the engineers' locations. The algorithm proposed in this study allows establishing the optimal locations. Therefore, a design center could obtain more energy by using a specific number of EVs as described in Section 4.4;

(b.3) The contribution of V2G to the building energy demand ranges between $0.5 \%$ and $1.3 \%$ when using the algorithm proposed in this study in a small design center (Section 3.2).

(c) V2G and Vehicle-to-home (V2H) compatibility Even though battery performance is not degraded due to charging and discharging processes, current policies keep the user from participating in $\mathrm{V} 2 \mathrm{G}$ and $\mathrm{V} 2 \mathrm{H}$ at the same time. The EV charging fee is higher than the savings obtained when using V2H. Consequently, V2G is not compatible with V2H. However, policies cannot be changed if the power of renewable energy installed is not increased. Therefore, renewable energy mix vs. non-renewable energy is not high enough. Consequently, the policies to promote EVs are as important as increasing the power of the renewable energy installed (Sections 3.3 and 4.2)

(d) Cybersecurity As detailed in the cybersecurity section, some policies to assure that an electronic control unit (ECU) is not violated imply that the electronic control unit is no longer available. In this present study, $190 \mathrm{~kg}$ of waste is generated every year taking into account the electronic control units scrapped. Consequently, some techniques used for ECU cybersecurity are not eco-friendly, and more research should be done into this topic to better integrate cybersecurity and eco-design (Section 3.4).

Supplementary Materials: The following are available online at http://www.mdpi.com/1996-1073/13/15/3997/s1, A beta version of the application coded in Python is provided. The full version cannot be provided as the company which has collaborated in this study has not authorized it. The measurements obtained when driving EVs are not provided as the company which has collaborated in this study has not authorized it.

Author Contributions: D.B.-D. and P.M.O.-C. were primarily responsible for creating this manuscript. D.B.-D. and P.M.O.-C. were responsible for creating the application in Python and obtained all measurements performed in this research. A.C.-S. and J.-J.B.-P. analyzed the data obtained as well as policies and collected data and information from the French System Operator. All authors have read and agreed to the published version of the manuscript.

Funding: This research received no external funding.

Conflicts of Interest: The authors declare no conflict of interest.

\section{Appendix A How to Configure the Calls to Here ${ }^{\circledR}$ API}

Here ${ }^{\circledR}$ API is able to provide a great deal of information about how to go from A to B. However, the calls to the Here ${ }^{\circledR}$ API must be done properly. In this research, the API is called by using the pseudocode shown in Figure A1. The string PARAM must be built. The following parameters are indicated:

(A) apiKey. This key is generated when a user is registered on the Here ${ }^{\circledR}$ developers' website. Replace XXXX by your key;

(B) Waypoint0 and waypoint 1 contain the latitude and longitude information about the origin and destination locations which are stored in the location_coor dictionary in Python. The Geopy package can be used to obtain coordinates;

(C) Mode. This parameter contains important information for the Here ${ }^{\circledR}$ API such as the type of route (the fastest, the shortest) and traffic state;

(D) As stated in Section 2, a consumption model has to be indicated by using consumptionmodel and customsonsumptiondetails. 
The response variable stores the answer from the Here ${ }^{\circledR}$ server.

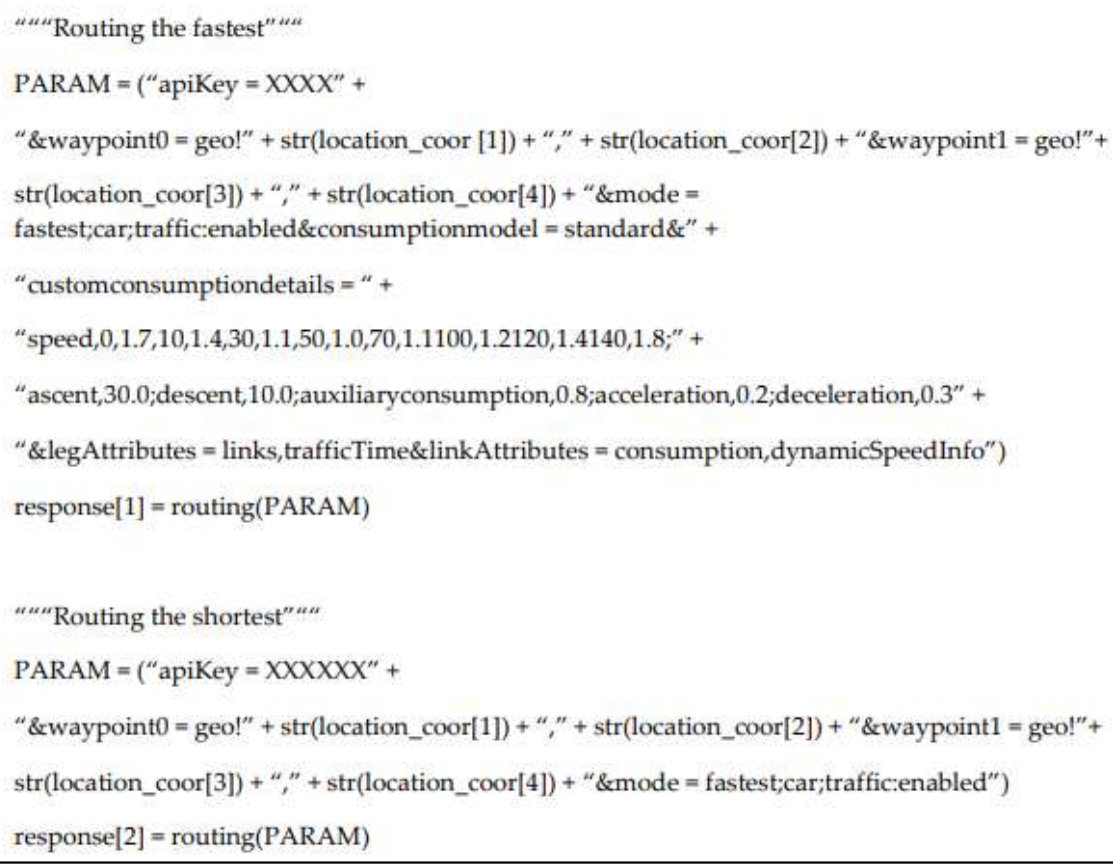

Figure A1. Pseudocode to obtain the desired Here ${ }^{\circledR}$ answer.

The answer from Here ${ }^{\circledR}$ is a json file. The reader can find a great deal of information such as the speed estimation taking into account traffic conditions (trafficSpeed parameter), time elapsed for a specific speed and consumption, etc. The reader can easily estimate the average consumption in $\mathrm{kWh}$, the average speed, etc.

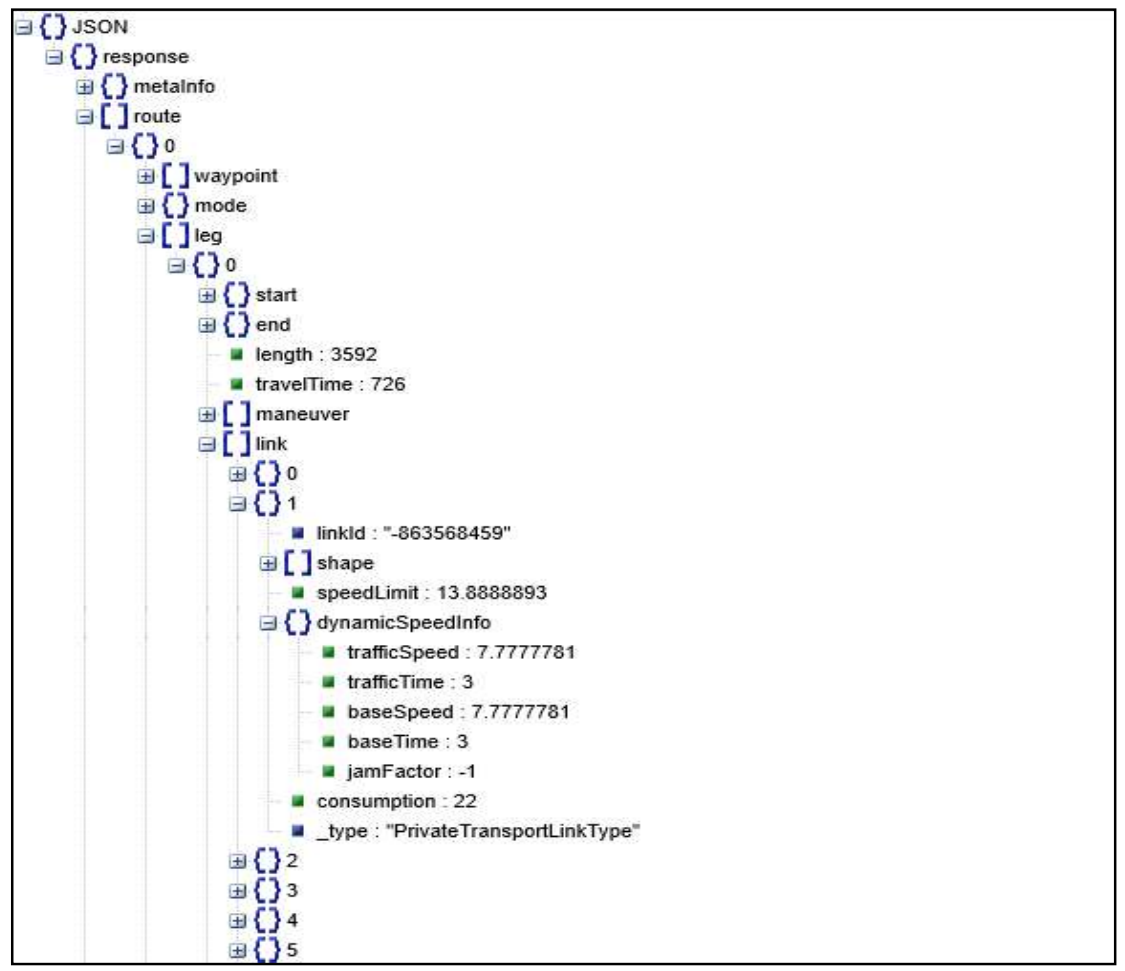

Figure A2. Here ${ }^{\circledR}$ answer. Json format. 


\section{References}

1. European Union Website. Available online: https://ec.europa.eu/growth/industry/sustainability/ecodesign en (accessed on 2 May 2020).

2. Sustainability Guide Founded by European Union. Available online: https://sustainabilityguide.eu/ecodesign/ (accessed on 3 May 2019).

3. Chun, Y.; Lee, K.; Lee, J.S.; Lee, J.Y.; Lee, M.H.; Mishima, N.; Tahara, K. Identifying key components of products based on consumer- and producer-oriented eco-design indices considering environmental impacts, costs, and utility value. J. Clean. Prod. 2018, 198, 1031-1043. [CrossRef]

4. Cicconi, P. Eco-design and Eco-materials: An interactive and collaborative approach. Sustain. Mater. Technol. 2020, 23, 135. [CrossRef]

5. Götze, U.; Peças, P.; Richter, F. Design for eco-efficiency-A system of indicators and their application to the case of moulds for injection moulding. Procedia Manuf. 2019, 33, 304-311. [CrossRef]

6. Peiris, R.L.; Kulatunga, A.K.; Jinadasa, S.N. Conceptual model of Life Cycle Assessment based generic computer tool towards Eco-Design in manufacturing sector. Procedia Manuf. 2019, 33, 83-90. [CrossRef]

7. de Grave, A.; Olsen, S.I. Challenging the sustainability of micro product development. In $4 M$ Second International Conference on Multi-Material Micro Manufacture; Springer: New York, NY, USA, 2006.

8. Morgan, J.M.; Liker, J.K. The Toyota Product Development System: Integrating People, Process, and Technology; Productivity Press: New York, NY, USA, 2006.

9. Rosen, M.A.; Kishawy, H.A. Sustainable Manufacturing and Design: Concepts, Practices and Needs. Sustainability 2012, 4, 154-174. [CrossRef]

10. European Court of Auditors. Available online: https://www.eca.europa.eu/Lists/ECADocuments/SR20_01/ SR_Ecodesign_and_energy_labels_EN.pdf (accessed on 2 April 2020).

11. Seow, Y.; Goffin, N.; Rahimifard, S.; Woolley, E. A ‘Design for Energy Minimization' approach to reduce energy consumption during the manufacturing phase'. Energy 2016, 109, 894-905. [CrossRef]

12. Ka-Leung-Moon, K.; Youn, C.; Chang, J.M.T.; Yeung, A.W. Product design scenarios for energy saving: A case study of fashion apparel. Int. J. Prod. Econ. 2013, 146, 392-401. [CrossRef]

13. United Nations Environment Program. 2009. Available online: http://www.d4s-sbs.org/d4s_sbs_manual_ site_S.pdf (accessed on 2 April 2020).

14. Tecchio, P.; Ardente, F.; Marwede, M.; Clemm, C.; Dimitrova, G.; Mathieux, F. Ecodesign of Personal Computers: An Analysis of the Potentials of Material Efficiency Options. Procedia CIRP 2018, 69, 716-721. [CrossRef]

15. Nina, W.; Patricia, L.; Francesco, O. 2018. Available online: http://oro.open.ac.uk/52888/ (accessed on 2 April 2020).

16. Naumann, S.; Kern, E.; Dick, M.; Joham, T. 2015. Available online: https://files.ifi.uzh.ch/hilty/t/Literature_ by_RQs/RQ\%20120/2015_Naumann_Kern_Dick_Sustainable\%20Software\%20Engineering.pdf (accessed on 3 February 2019).

17. Cao, X.; Dai, X.; Liu, J. Building energy-consumption status worldwide and the state-of-the-art technologies for zero-energy buildings during the past decade. Energy Build. 2016, 128, 198-213. [CrossRef]

18. Colin, C.V.; Capilla, R.; Betz, S.; Penzenstadler, B.; Crick, T.; Crouch, S.; Nakagawa, E.Y.; Becker, C.; Carrillo, C. Software sustainability: Research and practice from a software architecture viewpoint. J. Syst. Softw. 2017, $138,174-188$.

19. Nurcan, S.; Soffer, P.; Bajec, M.; Eder, J. Advanced Information Systems Engineering. In Proceedings of the 28th International Conference, CAiSE, Ljubljana, Slovenia, 13-17 June 2016; Springer: New York, NY, USA, 2016; pp. 35-36.

20. Ellis, G. Control System Design Guide, 1st ed.; Springer: New York, NY, USA, 2012.

21. Rajeev, R.; Kasun, H.; Rehan, S. Improving the energy efficiency of the existing building stock: A critical review of commercial and institutional buildings. Renew. Sustain. Energy Rev. 2016, 53, 1032-1045.

22. Bui, D.; Ngoc-Nguyen, T.; Ghazlan, A.; Ngo, N.; Duc-Ngo, T. Enhancing building energy efficiency by adaptive façade: A computational optimization approach. Appl. Energy 2020, 2020, 114797. [CrossRef]

23. Zeyu, W.; Ravi, S.S. Classification of Household Appliance Operation Cycles: A Case-Study Approach. Energies 2015, 8, 10522-10536. 
24. Qi, X.; Wu, G.; Barth, M.J.; Boriboonsomsin, K. Energy Impact of Connected Eco-driving on Electric Vehicles. In Road Vehicle Automation 4, 2nd ed.; Beiker, S., Gereon, M., Eds.; Springer: Nueva York, NY, USA, 2017; Volume 4, pp. 97-111.

25. HAL. Available online: https://hal.archives-ouvertes.fr/hal-01405291/document (accessed on 12 March 2020).

26. Vezzoli, C.; Ceschin, F.; Osanjo, L.; M'Rithaa, M.K.; Moalosi, R.; Nakazibwe, V.; Diehl, J.C. Desgin for Sustainability. An Introduction; Springer: New York, NY, USA, 2018; pp. 20-28.

27. Nunzio, G.; Thibault, L.; Sciarretta, A. A model-based eco-routing strategy for electric vehicles in large urban networks. In Proceedings of the International Conference on Intelligent Transportation Systems, Rio de Janeiro, Brazil, 1-4 November 2016. [CrossRef]

28. University of California. Available online: https://escholarship.org/uc/item/9z18z7xq (accessed on 25 September 2019).

29. Haque, A.; Rahman, M.A. Study of a solar PV-powered mini-grid pumped hydroelectric storage \& its comparison with battery storage. In Proceedings of the 7th Electrical \& Computer Engineering (ICECE), Dhaka, Bangladesh, 20-22 December 2012.

30. Haque, A.; Rahman, M.A.; Ahsan, Q. Building Integrated Photovoltaic system: Cost effectiveness. In Proceedings of the 7th International Conference on Electrical and Computer Engineering, Dhaka, Bangladesh, 20-22 December 2012.

31. Tarroja, B.; Li, Z.; Wifvat, V.; Shaffer, B.; Samuelsen, S. Assessing the stationary energy storage equivalencyicle-to-gri.d charging battery electric vehicles. Energy 2016, 106, 673-690. [CrossRef]

32. Yang, Z.; Noori, M.; Tatari, O. Vehicle to Grid regulation services of electric delivery trucks: Economic and environmental benefit analysis. Appl. Energy 2016, 170, 161-175.

33. Uddin, K.; Dubarry, M.; Glick, M.B. The viability of vehicle-to-grid operations from a battery technology and policy perspective. Energy Policy 2018, 113, 342-347. [CrossRef]

34. Sovacool, B.; Noel, L.; Axsen, J.; Kempton, W. The neglected social dimensions to vehicle-to-grid (V2G) transition: A critical and systematic review. Environ. Res. Lett. 2018. Available online: https://iopscience.iop. org/article/10.1088/1748-9326/aa9c6d (accessed on 10 March 2020).

35. HERE. Available online: https://developer.here.com/ (accessed on 29 March 2020).

36. HERE. Available online: https://developer.here.com/documentation/routing/dev_guide/topics/resourceparam-type-custom-consumption-details.html (accessed on 29 March 2020).

37. De Cauwer, C.; Van Mierlo, J.; Coosemnans, T. Energy Consumption Prediction for Electric Vehicles Based on Real-World Data. Energies 2015, 8, 8573-8593. [CrossRef]

38. ETAS (Bosch®) Website. Available online: https://www.etas.com/en/products/inca_software_products.php (accessed on 8 December 2019).

39. Open Charge Map. Available online: https://openchargemap.org/site (accessed on 15 May 2020).

40. ETAS (Bosch®) Website. Available online: https://www.etas.com/en/products/mda.php (accessed on 15 March 2020).

41. Palma-Mendez, J.T.; Marín-Morales, R. Inteligencia Artificial, 2nd ed.; Mc Graw Hill: New York, NY, USA, 2008; pp. 647-691.

42. Hagan, M.T.; Demuth, H.B.; Beale, M.H.; de Jesús, O. Neural Network Design, 2nd ed.; Martin Hagan: Oklahoma, OK, USA, 2012; pp. 14.1-14.48.

43. Mathworks. Available online: https://es.mathworks.com/help/deeplearning/ref/narnet.html;jsessionid= 1b35de9b0f7625f9bcc764bb5ac5 (accessed on 28 January 2020).

44. Ponce-Cruz, P. Inteligencia Artificial, 1st ed.; Marcombo: Barcelona, Spain, 2011; pp. 238-265.

45. Russel, E.; Yuhui, S. Computational Intelligence, 2nd ed.; Morgan Kaufmann: San Francisco, CA, USA, 2011; pp. 197-265.

46. French System Operator. Available online: https://www.rte-france.com/fr/eco2mix/eco2mix-co2 (accessed on 15 February 2020).

47. Baca-Ruiz, L.G.; Pegalajar-Cuéllar, M.; Delgado Calvo-Flores, M.; Pegalajar-Jiménez, M. An Application of Non-Linear Autoregressive Neural Networks to Predict Energy Consumption in Public Buildings. Energies 2016, 9, 684. [CrossRef]

48. French Ministry of Ecologic Transition. Available online: https://www.statistiques.developpementdurable.gouv.fr/sites/default/files/2019-05/datalab-53-chiffres-cles-des-energies-renouvelables-edition2019-mai2019.pdf (accessed on 8 May 2020). 
49. The International Council on Clean Transportation. Available online: https://www.sciencedirect.com/ (accessed on 8 May 2020).

50. Kester, J.; Noel, L.; Zarazua de Rubens, G.; Sovacool, B.K. Promoting Vehicle to Grid (V2G) in the Nordic region: Expert advice on policy mechanisms for accelerated diffusion. Energy Policy 2018, 116, 422-432. [CrossRef] 